\title{
Addressing the Complexity of Tourette's Syndrome through the Use of Animal Models
}

\author{
Ester Nespoli ${ }^{1,2 *}$, Francesca Rizzo ${ }^{2,3 * t}$, Tobias M. Boeckers ${ }^{3}$, Bastian Hengerer ${ }^{1}$ and \\ Andrea G. Ludolph ${ }^{2}$ \\ ${ }^{1}$ Competence in Neuro Spine Department, Boehringer Ingelheim Pharma GmbH \& Co. KG, Biberach an der Riss, Germany, \\ ${ }^{2}$ Department of Child and Adolescence Psychiatry/Psychotherapy, University of Ulm, UIm, Germany, ${ }^{3}$ Institute of Anatomy \\ and Cell Biology, University of UIm, UIm, Germany
}

Tourette's syndrome (TS) is a neurodevelopmental disorder characterized by fluctuating motor and vocal tics, usually preceded by sensory premonitions, called premonitory urges. Besides tics, the vast majority-up to 90\% - of TS patients suffer from psychiatric comorbidities, mainly attention deficit/hyperactivity disorder (ADHD) and obsessive-compulsive disorder (OCD). The etiology of TS remains elusive. Genetics is believed to play an important role, but it is clear that other factors contribute to TS,

OPEN ACCESS

Edited by:

Peristera Paschou,

Democritus University of Thrace,

Greece

Reviewed by:

Izhar Bar-Gad,

Bar-llan University, Israel Kirsten R. Müller-Vahl,

Medical School of Hannover, Germany

${ }^{*}$ Correspondence:

Ester Nespoli

ester.nespoli@uni-ulm.de;

Francesca Rizzo

francesca.rizzo@uni-ulm.de

${ }^{\dagger}$ These authors have contributed equally to this work.

Specialty section:

This article was submitted to Child and Adolescent Psychiatry, a section of the journal

Frontiers in Neuroscience

Received: 04 December 2015 Accepted: 16 March 2016

Published: 08 April 2016

Citation:

Nespoli E, Rizzo F, Boeckers TM, Hengerer B and Ludolph AG (2016)

Addressing the Complexity of

Tourette's Syndrome through the Use of Animal Models.

Front. Neurosci. 10:133 doi: 10.3389/fnins.2016.00133 possibly altering brain functioning and architecture during a sensitive phase of neural development. Clinical brain imaging and genetic studies have contributed to elucidate TS pathophysiology and disease mechanisms; however, TS disease etiology still is poorly understood. Findings from genetic studies led to the development of genetic animal models, but they poorly reflect the pathophysiology of TS. Addressing the role of neurotransmission, brain regions, and brain circuits in TS disease pathomechanisms is another focus area for preclinical TS model development. We are now in an interesting moment in time when numerous innovative animal models are continuously brought to the attention of the public. Due to the diverse and largely unknown etiology of TS, there is no single preclinical model featuring all different aspects of TS symptomatology. TS has been dissected into its key symptomst hat have been investigated separately, in line with the Research Domain Criteria concept. The different rationales used to develop the respective animal models are critically reviewed, to discuss the potential of the contribution of animal models to elucidate TS disease mechanisms.

Keywords: tics, repetitive behavior, genetics, environment, PPI, TS comorbidities

\section{INTRODUCTION}

\section{TS Definition, Epidemiology, Symptoms, and Natural Course}

Tourette's Syndrome (TS) was named after Georges Gilles de la Tourette (1857-1904) who first described it as a "tic syndrome" in 1885 and whose observations are still considered mostly valid today. Tics are involuntary movements or vocalizations that can involve different parts of the body changing in frequency, intensity and duration. A diagnose of TS requires the presence of both

Abbreviations: ADHD, Attention Deficit/Hyperactivity Disorder; CSTC, Cortico-striato-thalamo-cortical circuit; DA, Dopamine; DOI, 2,5-Dymethoxy-4-iodoamphetamine; DR, Dopaminergic Receptor; DSM-5, Diagnostic and Statistical Manual of Mental Disorders, Fifth Edition; GABA, Gamma-Aminobutyric acid; GPe, Globus pallidus externus; HDC, Histidine decarboxylase; KO, Knock-out; NTs, Neurotransmitters; OCD, Obsessive-Compulsive Disorder; PPI, Pre-Pulse Inhibition; PU, Premonitory Urge; TS, Tourette’s Syndrome. 
multiple motor and one or more vocal tics with an onset before age 18 years and a persistence for at least 1 year (DSM-5).

But TS is not only about tics: up to $90 \%$ of all TS patients experience psychiatric comorbidities, mainly Attention Deficit/Hyperactivity Disorder (ADHD) and obsessive compulsive disorder (OCD), but also depression, anxiety disorders, conduct disorders, personality disorders, and selfinjurious behaviors (Khalifa and Knorring, 2007; Cavanna et al., 2009; Pallanti et al., 2011).

TS has long been considered to be rare, as it was reported to affect only 1 in 2000 (Bruun, 1984). Nowadays the prevalence of TS in the general population has been re-evaluated, and is estimated to be $0.4-1 \%$ (Robertson et al., 2009), but could be even higher since, especially in childhood, tics are often so mild that are hardly perceived and easily overlooked. In many cases only an expert eye is able to identify tics in patients presented to the clinician as a consequence of behavioral problems or ADHD.

\section{Role of CSTC Circuitry in TS Pathophysiology}

The exact neurobiological background of TS remains still unclear, but a central role of the cortico-striato-thalamo-cortical (CSTC) circuit appears uncontroversial, as numerous anatomical and functional imaging studies were able to detect morphological and functional alterations in CSTC components of TS patients compared to controls (Singer et al., 1993; Peterson et al., 2003; Sowell et al., 2008).

The pre-motor and motor cortices, the striatum, composed of caudate and putamen, the globus pallidus internus (GPi) and externus (GPe), the subthalamic nucleus (STN), the thalamus, and the substantia nigra (SN) are connected in the CSTC circuit. Under physiological circumstances, an activation of this circuit physiologically results in voluntary movements, while involuntary movements are repressed.

Movements occur as the motor cortex is activated by the thalamus, which is controlled by the STN-GPe-GPi microcircuit. When the pre-motor cortex activates the putamen, the inhibitory striatal projection neurons release the thalamus from inhibition held by the STN-GPe-GPi, and eventually the motor cortex can be activated, leading to movement (Obeso and Lanciego, 2011).

Tics are supposed to be caused by a deregulated activity of the basal ganglia, which consequentially leads to disinhibition of the thalamus and a hyperexcitability of the motor cortex (Albin and Mink, 2006; Wang et al., 2011).

When the beneficial effect of dopaminergic modulators such as haloperidol and pimozide on tic management was observed, a dysfunction in the dopaminergic system was seen as the main responsible of TS neuropathology (for review see Buse et al., 2013). Nowadays the use of haloperidol and pimozide has been gradually left aside in favor of the better tolerable atypical antipsychotics and atypical neuroleptics, such as aripiprazole or risperidone, acting on dopamine and serotonin. In general, there is growing evidence indicating that TS is not a pure DA-related disorder, and the interplay of other neurotransmitters is strongly supported to contribute or cause the disease (for review see Udvardi et al., 2013; Figure 1).

\section{Importance of a TS Animal Model}

In vivo animal models are important tools to challenge and validate pathophysiological hypotheses and test new therapeutic options. An animal model is constructed to fulfill one or more of the following parameters: face validity (ability to show similar symptoms to the patients' ones), construct validity (model developed according to a rationale matching the pathological hypothesis), and predictive validity (model responds to a treatment similarly to patients). The ideal model is able to show all these three features, but in most cases the main focus remains on one of the three aspects. The use of animal models could help the major means of investigations of TS thanks to their ability to verify pathophysiological hypotheses and test pharmacological compounds.

\section{METHODS}

This article is a review about the "now-in-use" preclinical models of TS, extracted from the literature of the last decade. As a perfect model for TS has not yet been produced, we aim at showing the different successful methods used by researchers to independently model all major aspects involved in TS pathology, that we separately describe and analyze. Strengths and limitations of animal models are explained with a focus on recent research findings. The aim is to provide up-to-date information on TS animal models for students, researchers, and clinicians, and hints to be used by preclinical experimenter in developing new TS animal models.

Electronic literature search via MEDLINE/PubMed has been conducted for articles that had been published in English since year 2000. Combinations of keywords were used to identify relevant articles, including: "Tourette Syndrome," "TS animal model," "TS in vivo," "motor tic," "stereotype," "premonitory urge," "PPI," “genetic TS," “environment TS," “immune TS," "ADHD," "TS neurobiology," "OCD." Systematic and narrative reviews, as well as original research articles were included. The last search was conducted on November 2015. The literature search was also supplemented with key publications and book chapters known to the authors.

\section{TS PHENOMENOLOGY}

\section{Genetics}

TS has a strong genetic basis. Family studies in children with TS reveal that $8-57 \%$ of their parents had a history of tics, and firstdegree relatives had a significant increased risk of developing the disorder (Pauls et al., 1991). Twin studies also report a 53-56\% concordance rate for TS in monozygotic twins, compared with only $8 \%$ in dizygotic twins (Price et al., 1985; Hyde et al., 1992).

The initial idea of TS being a monogenic Mendelian disorder has been quickly revised and TS is now considered a complex disorder with many open questions regarding its overall genomic architecture. The identification of TS-related genes through linkage and association studies is hindered by the unclear mode of inheritance, the genetic heterogeneity of the disease and its apparently incomplete penetrance (Pauls, 2003). 


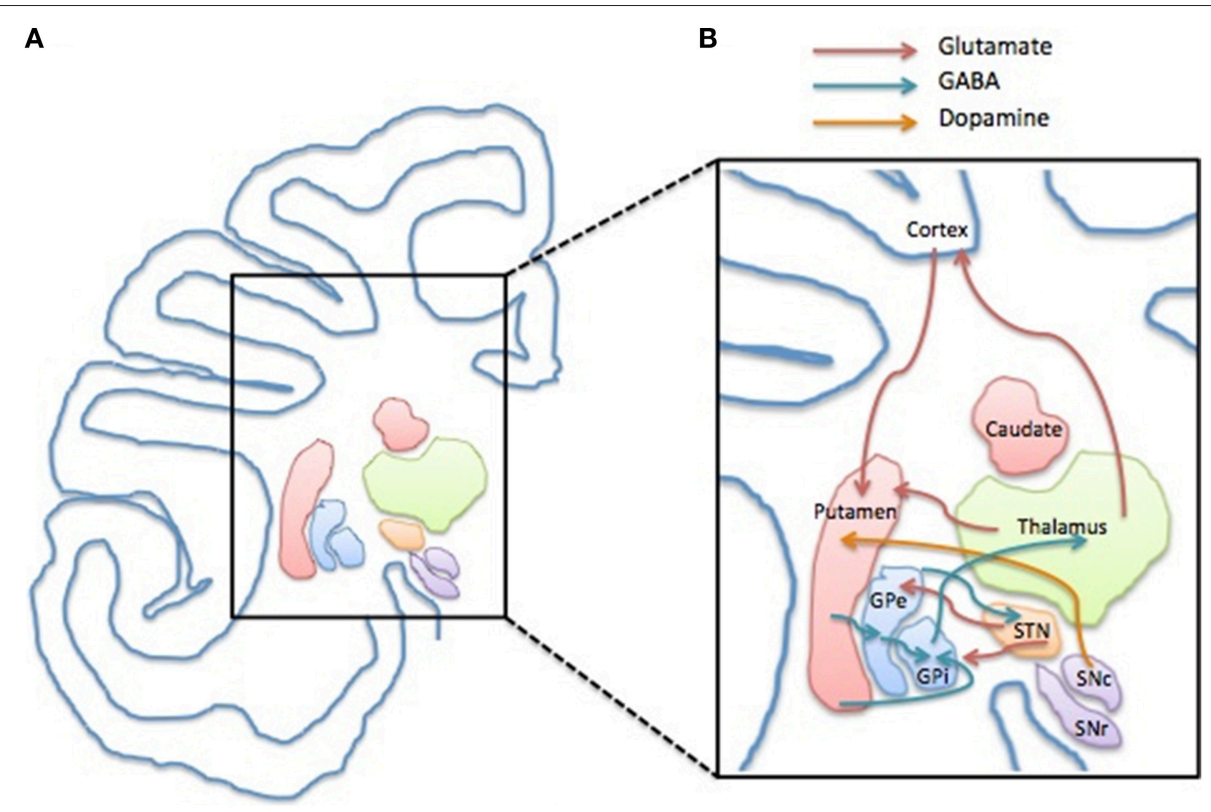

FIGURE 1 | Structure and compartments of CSTC circuit. (A) Representation of a left side of human brain coronal section depicting the anatomical localization of the basal ganglia components and the cerebral cortex. (B) Schematic illustration of the CSTC internal network within the circuit depicting the glutamatergic (red arrow), GABAergic (blue arrow) and the dopaminergic connection (yellow arrow). Abbreviations: GPe, Globus Pallidus pars externa; GPi, Globus Pallidus pars interna; STN, Nucleus Subtalamicus; SNc, Substantia Nigra pars compacta; SNr, Substantia Nigra pars reticulata.

Specific genetic abnormalities have so far been identified in less than $1 \%$ of patients, including polymorphisms and copy number variation. Many of these findings also parallel those of other common neuropsychiatric and neurodevelopmental disorders, unveiling previously unknown disease mechanisms, but their specific role for TS has rarely been elucidated (Sundaram et al., 2010; Crane et al., 2011; Scharf et al., 2013; Bertelsen et al., 2015).

\section{Modeling TS Genetics}

Animal genetic manipulation has widely been a key starting point to model numerous diseases.

Sequence variants in Slirtk 1 were found in TS patients and associated to loss of function in supporting dendritic growth during development of numerous components of CSTC circuit (Abelson et al., 2005). Slitrk1 KO mice exhibit elevated anxietyand depression-like behaviors, symptoms which have also been associated withTS-spectrum disorder (Katayama et al., 2010).

The discovery of a mutation in the histidine decarboxylase $(H d c)$ gene in a unique family with marked history of tic disorders lead to the investigation of the disruption of histaminergic pathway in animal models. The core phenomenology of TS, ticlike behaviors, are not observed in $H d c \mathrm{KO}$ mice at baseline, but stereotypies as repetitive sniffing and orofacial movements can be elicited by activating the dopamine system with $\mathrm{D}$-amphetamine and are ameliorated after intracerebral administration of dopamine antagonist haloperidol. Fear conditioning significantly increased grooming in these animals (Castellan Baldan et al., 2014) $)^{1}$.

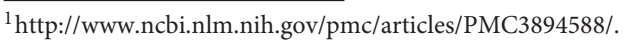

Furthermore, significant pre-pulse inhibition (PPI) deficits and striatal dopamine dysregulation have also been observed in $\mathrm{Hdc} \mathrm{KO}$ mice, aligning human findings and supporting the interplay between histamine and dopamine, the major known player in TS (Rapanelli et al., 2014; Xu et al., 2015a).

Another recent genetic TS animal model has been developed based onthe observation that cholinergic interneurons are reduced by $50 \%$ in TS patient's striatum (Kataoka et al., 2010; Lennington et al., 2014): region-specific knockout of choline acetyltransferase in the dorsolateral striatum led to stressinduced increase in grooming. D-amphetamine administration did not increase the amount of grooming activity, but the animals performed more repetitive stereotyped actions (Xu et al., 2015b) $)^{2}$.

A main regulator of striatal activity is dopaminergic system whose alterations have been correlated with TS severity and the development of comorbidities. Genetic manipulation has been used as tool to address dopaminergic contribution to the pathology, even though genetic evidence for dopaminergic dysfunction has not been found in TS patients yet. Dopamine transporter (DAT) KO mice (Berridge et al., 2005) and dopamine receptor 3 (DR3) KO mice (Garner and Mason, 2002) are characterized by a hyperdopaminergic condition and show stereotypies, consolidating their role in repetitive behavior. Furthermore, DAT KO mice show a more complex and rigid sequence of actions during grooming, which is in between tics of TS and compulsions of OCD.

The lack of a clear, spontaneous "ticcing" phenotype in these genetic animal models raises the question of further

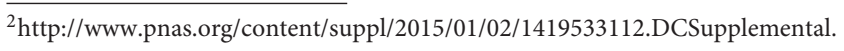


neurotransmitters, synaptic, or developmental mechanisms that need to be evaluated (Table 1).

\section{Tics}

A tic is a sudden, rapid, recurrent, non-rhythmic, jerk-like movement, or vocalization that can vary in frequency, intensity, duration and anatomical localization. Tics are classified as simple or complex according to the number of groups of muscles involved, and as motor or vocal tics.

Simple tics usually last few milliseconds engage one or a group of muscles like those involved in eye blinking (simple motor tic) or throat clearing (simple vocal tics). Complex tics last few seconds and can be defined as a combination of simple tics. They can appear purposeful like performing obscene gesture (copropraxia) or uttering racial slurs (coprolalia) or may consist in the imitation of someone elses' actions (echopraxia) or words (echolalia).

Three different tic disorders are included in the DSM-5: provisional tic disorder, persistent motor, or vocal tic disorder and TS. The difference between these disorders relies on the type of tics observed (motor, vocal, or both), and how long the symptoms have lasted. The presence of both motor and vocal tics for a period longer then 1 year since first onset (before 18 years of age) and their "waxing and waning" course differentiate TS. Indeed, they may show a pattern in which old and new tics overcome and fluctuate in frequency and intensity over time.

Other hyperkinetic movements can occur in TS patients and can be easily misdiagnosed and lead to a wrong treatment approach (Kompoliti and Goetz, 1998). This is the case of stereotypies that are fixed, prolonged and rhythmic repetitive behaviors and present an average age of onset of 3 years (DSM-5). Unlike stereotypies, tics are tipically preceded by an uncomfortable phenomenon called "premonitory urge" (PU) and can be voluntarily suppressed by most patients for a short period of time.

In general, tics are intensified by stress, anxiety, excitement, anger, fatigue, or infections (Lombroso et al., 1991; Nelson, 1993; Lin et al., 2007) while their reduction is reported in patients performing focused and effortful activities (Conelea and Woods, 2008).

\section{Modeling Tics}

The clear terminology available for clinicians to identify motor disorders is not easily applicable by in vivo experimenters, as any parallelism between human and animal condition must be taken carefully.

Literature testifies the lack homogeneity employed to name motor phenotypes in animal models of TS, ranging from "tic," to "tic-like movement," or "repetitive movements" and "stereotypies."

Several animal models of tics have been obtained through systemic or focal administration of active substances, which give a transient but easy to replicate phenotype. Importantly, different compounds with diverse effects were proven to be effective in the induction of tic-like behavior.

The intracerebral infusion of GABAergic antagonists is becoming a more and more appealing strategy of tic-like movement induction and has led to the formulation of the

TABLE 1 | Genetic animal models of TS.

\begin{tabular}{|c|c|c|c|c|}
\hline Transgenic Model & Gene target & Association to TS & Phenotype & References \\
\hline Slitrk1 KO mouse & $\begin{array}{l}\text { SLIT and NTRK-like } \\
\text { protein1 }\end{array}$ & Slitrk1 mutated variants & $\begin{array}{l}\text { Anxiety-like and depression-like behavioral abnormalities } \\
\text { attenuated by clonidine ( } \alpha 2 \text { adrenergic agonist) treatment }\end{array}$ & Katayama et al., 2010 \\
\hline HDC-KO mouse & $\begin{array}{l}\text { Histidine } \\
\text { Decarboxylase }\end{array}$ & $\begin{array}{l}\text { HDC nonsense } \\
\text { mutation }\end{array}$ & $\begin{array}{l}\text { Increased grooming after D- amphetamine (5-HTR } \\
\text { agonist) administration or stress. Stereotypies in HDC } \\
\text { KO mice are mitigated by haloperidol (DA agonist) } \\
\text { pretreatment }\end{array}$ & $\begin{array}{l}\text { Castellan Baldan et al., } \\
2014\end{array}$ \\
\hline ChAT-ablated mouse & $\begin{array}{l}\text { Choline } \\
\text { acetyltransferase }\end{array}$ & $\begin{array}{l}\text { Reduced cholinergic } \\
\text { interneurons in striatum } \\
\text { of TS patients }\end{array}$ & $\begin{array}{l}\text { No tic-like stereotypies and PPI deficit at baseline; } \\
\text { increased and fragmented grooming after acoustic } \\
\text { startle stimuli; increased stereotypies after amphetamine } \\
\text { (5-HTR agonist) administration }\end{array}$ & Xu et al., 2015b \\
\hline \multirow[t]{3}{*}{ DAT-KO mouse } & Dopamine transporter & - & Hyperdopaminergia in striatum and supestereotypies. & Berridge et al., 2005 \\
\hline & & & DA/5-HT imbalance in basal ganglia & Pogorelov et al., 2005 \\
\hline & & & PPI deficits and perseverative motor patterns & Ralph et al., 2001 \\
\hline \multirow[t]{2}{*}{ DRD3-KO mouse } & Dopamine receptor D3 & - & Increase in spontaneous stereotypies & $\begin{array}{l}\text { Garner and Mason, } \\
2002\end{array}$ \\
\hline & & & $\begin{array}{l}\text { Hyperlocomotor activity after amphetamine (5-HTR } \\
\text { agonist) treatment }\end{array}$ & McNamara et al., 2006 \\
\hline DRD3-KO rat & & - & Hyperactivity and rotational behaviors & \\
\hline
\end{tabular}

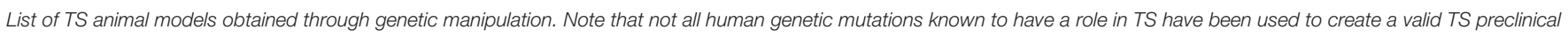

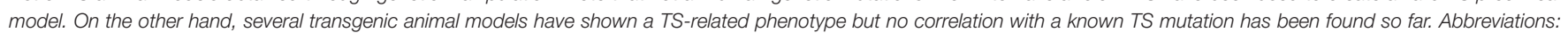

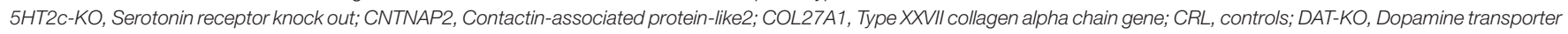

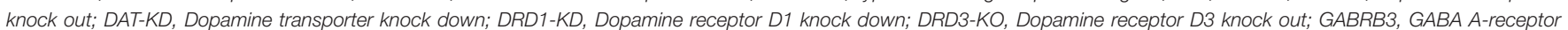

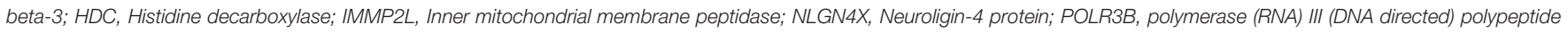
B; PPI, Pre-pulse Inhibition; SLITRK1, SLIT and NTRK-like protein1; 5-HTR, serotonin receptor. 
hypothesis that disequilibrium between cortical glutamatergic output and striatal GABAergic metabolism plays an important role in tic induction. The GPe was one of the first basal ganglia components to be investigated with this approach (Grabli et al., 2004), but is now the functional disruption of the striatum to be the major target of investigation.

Striatal injections of the GABAergic antagonist bicuculline in primates cause simple tic-like movements, hyperactivity and stereotyped behaviors (McCairn et al., 2009). These three phenotypes are independent processes and appear to be associated with different brain regions: the sensorimotor network, the prefrontal cortex and associative territories and the orbitofrontal cortex and limbic part of the basal ganglia respectively (Worbe et al., 2013). Electrophysiological data also suggest a role for the cerebellum in tic expression in this model (McCairn et al., 2013). The application of the same approach in adult rats results in an acute tic session that varies in intensity and body parts involved and is characterized by additional hyperactivity (Bronfeld et al., 2013) 3 $^{3}$ In mice, tics were also evoked by striatal picrotoxin injections, while cortical injections induce seizures (Pogorelov et al., 2015) ${ }^{4}$.

Systemic administration of hallucinogens acting on serotonin receptors (Tizabi et al., 2001; Fantegrossi et al., 2005, 2006; Halberstadt and Geyer, 2014; Ceci et al., 2015) induce headtwitches responses, while the use of monoamines modulators, induces stereotypies (Lv et al., 2009; Taylor et al., 2010). Stereotypic behaviors were also observed after administration of 3,3'-iminodipropionitrile (IDPN) (Wang et al., 2013) and Catha edulis extract (Oyungu et al., 2007).

The D1CT-7 transgenic mouse, originally proposed for OCD, shows head twitching and abnormal movements of limbs and trunk with juvenile onset and sexual dimorphism (Nordstrom and Burton, 2002). These animals display PPI deficits and ticlike manifestations that are increased in presence of spatial confinement-induced. This model appears to show higher hyperactive stress reduced by antipsychotics and clonidine (Nordstrom et al., 2015), making it the first model to show face validity for tics and feature also common TS-related phenotypes (Table 2).

\section{Premonitory Urge}

Since pediatric age, TS patients become aware of an uncomfortable sensation that precedes tics known as premonitory urge (PU) that, for about $57 \%$ of cases, is more bothersome then tics themselves (Cohen and Leckman, 1992; Reese et al., 2014).

From a therapeutic point of view, the understanding of PU might help tic management since it could enhance the patient's own ability to suppress it (Leckman et al., 1993; Frank and Cavanna, 2013).

In adult TS patients the neurophysiological system of urge and tic generation appears to be distinct from the one implied in tic control (Ganos et al., 2012): the urge would include both voluntary motor circuits and somatic sensation circuits

${ }_{3}^{3}$ http://www.frontiersin.org/Systems_Neuroscience/10.3389/fnsys.2013.00050/ abstract.

${ }^{4}$ http://www.sciencedirect.com/science/article/pii/S0014488615000035. (anterior cingulate cortex and supplementary motor area), while tic generation is known to take place in prefrontal structures involved in the primary inhibition of the motor control, as confirmed by neuroimaging studies (Peterson et al., 1998).

The genesis of PU is still unknown but some evidence led to the hypothesis that this feeling might reflect abnormalities of sensorimotor gating, i.e., the neurological process able to filter out redundant or unnecessary environmental stimuli that constantly reach our brain (Braff et al., 2001; Biermann-Ruben et al., 2012).

\section{Modeling TS Sensorimotor Gating Deficit}

Tics are, to a certain extent, an easy-to-detect phenomenon; PU is more complicated to be translated into a preclinical model but can be investigated through the study of sensorimotor gating deficit.

To assess sensorimotor gating functions, the pre-pulse inhibition (PPI) of the startle response is used in both humans and laboratory animals. PPI is a behavioral phenomenon in which a weak pre-stimulus (i.e., prepulse) diminishes the reaction to a subsequent stronger stimulus (i.e., pulse) that could otherwise trigger a strong startle response. In presence of acoustic, visual or tactile stimuli, TS patients show PPI deficits manifesting the inability to filter unnecessary information (Castellanos et al., 1996; Zebardast et al., 2013).

Due to its conformity to the validity criteria, this animal model of sensorimotor gating deficits has now reasonably been extended from the single research of schizophrenia (Wan and Swerdlow, 1996) to the study of TS and its comorbidities (Swerdlow and Sutherland, 2005). In rodents, PPI appears to be regulated by the nucleus accumbens and its dopaminergic activation. Similar to tics, PPI abnormalities develop in rats treated with dopaminergic agonists (Alsene et al., 2010; Mosher et al., 2015), hallucinogens (Swerdlow et al., 2003; Chen et al., 2012) and glutamate antagonists (Swerdlow et al., 2007; Pietraszek et al., 2009). PPI deficit could also be detected in spontaneous hypertensive rats (SHR), the model of choice for ADHD (Van Den Buuse, 2004; Table 3).

\section{Environmental Risk Factors}

Similar to other developmental neuropsychiatric disorders, TS perfectly fits in a so-called "multistrike model" of etiology. In this model the first hit is represented by the genetic vulnerability to the disease that is likely to be translated in structural and functional neurological changes. If these changes disturb regions with physiological self-regulatory functions -second hittic expression is evoked. In addition, various environmental factors (neuroendocrine, infectious, autoimmune, toxic, and psychosocial influences), representing a third strike, further increase the risk of tic expression (Spessot et al., 2004).

Numerous studies have investigated environmental factors that might contribute to the onset and severity of TS and associated comorbidities. Chao et al. (2014) systematically reviewed studies investigating the contribution of pre- and perinatal adverse events on onset and severity of TS and its comorbidities, if present.

Maternal smoking appears to be consistently implicated to TS pathology (Mathews et al., 2006; Motlagh et al., 2010). 


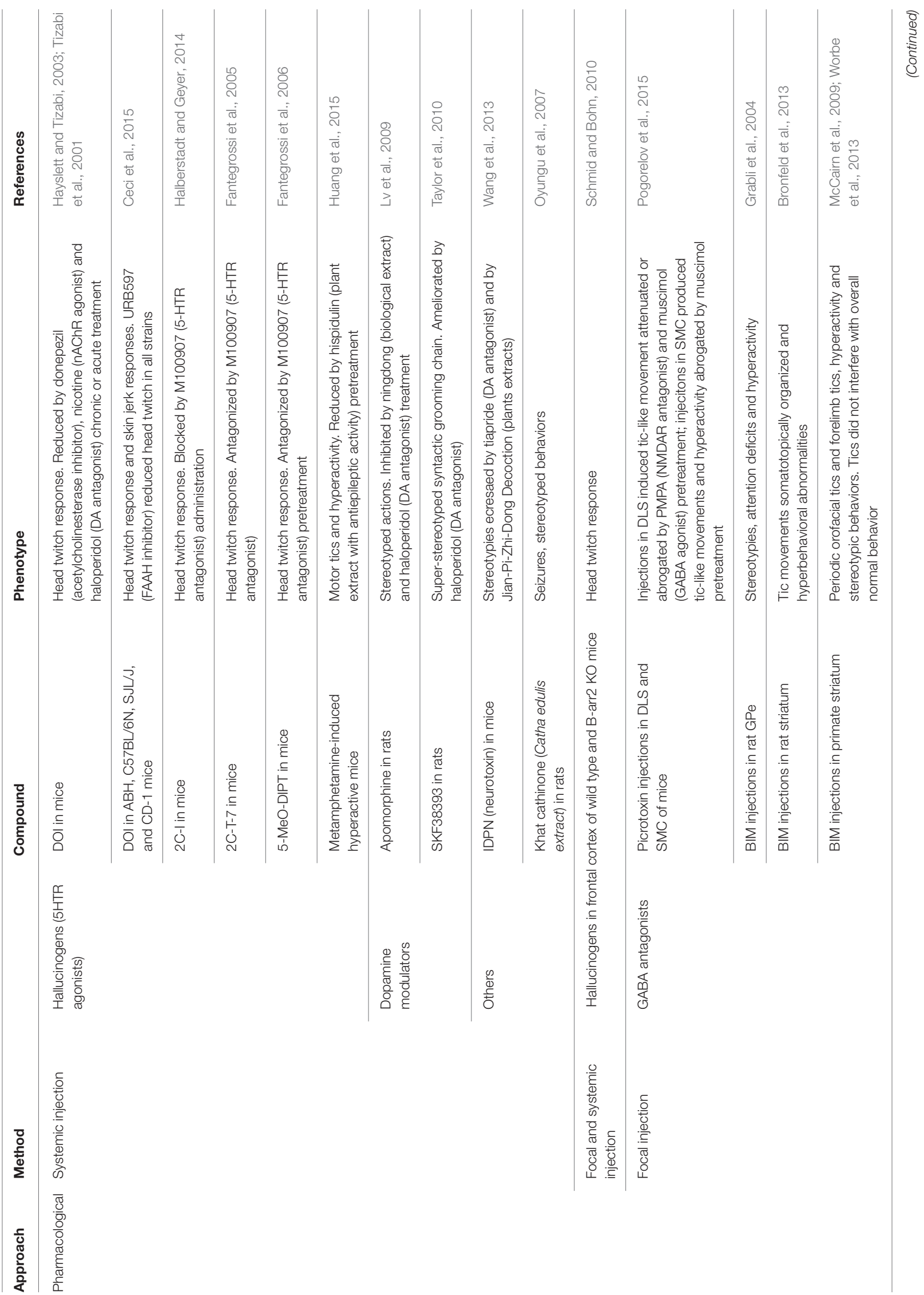


Infections, and particularly Pediatric Autoimmune Neuropsychiatric Disorders Associated with Streptococcal Infections (PANDAS) were associated to worsening or causing TS (Kurlan, 2004; Kirkman et al., 2008; Singer et al., 2012; Swedo et al., 2012), however, a causal relationship between streptococcal infections and TS is still under investigation (Hoekstra and Minderaa, 2005; Krause et al., 2010).

Finally, only a few clinical studies were conducted investigating the extent to which stressors affect TS patients' life (Silva et al., 1995) but TS patients report a strong link between stress and tics exacerbation. The hypothalamic-pituitary-adrenal axis is supported to have an enhanced responsivity in children with TS (Corbett et al., 2008) and tic severity seems to correlate to cortisol levels (Conelea and Woods, 2008).

\section{Modeling TS Environmental Risk Factors}

Several immune-mediated models have been developed according to different strategies.

Passive exposure to immunomediators (Ponzio et al., 2007; Smith et al., 2007; Depino et al., 2011; Patel et al., 2012; Zalcman et al., 2012) or to immunogenic microbial components (Hoffman et al., 2004; De Miranda et al., 2010; Yaddanapudi et al., 2010; Brimberg et al., 2012; Kirsten et al., 2012; Malkova et al., 2012) led to increased stereotypies and locomotion. However, additional deficits in motor coordination, learning/memory and social interaction, and the presence of immune deposits in the brain severely hamper their face validity for TS (Yaddanapudi et al., 2010).

Transplantation into naïve animals of antibodies derived from animals actively immunized with patients' sera (Taylor et al., 2002; Singer et al., 2005; Martin et al., 2008; Zhang et al., 2012) led to a similar phenotype and episodic vocalizations were reported (Hallett et al., 2000).

The importance of stress as a factor able to exacerbate tics has for long been referred by patients. Stress paradigms have proven capable of worsening the phenotype in animal models and have been recently introduced as a way to improve their validity (Xu et al., 2015a,b).

Stress paradigms can also be used to evaluate the ability of different stressors to predispose to abnormal behavioral development (Hall, 1998; Pryce and Feldon, 2003). For istance, maternal deprivation affects the social, emotional and attention domain of primates leading often to stereotypies or other dysfunctional motor activities (Márquez-Arias et al., 2010; Rommeck et al., 2011; Table 4).

\section{Related Psychiatric Conditions ADHD}

Attention-deficit/hyperactivity disorder (ADHD) is the most common comorbidity in TS.

$\mathrm{ADHD}$ is a neurodevelopmental disorder with an onset before age 12 (DSM-5). It affects about 5\% of children, with 2-4:1 boys/girls prevalence (Polanczyk and Rohde, 2007). The three core symptoms of ADHD are inattention, motor hyperactivity, and increased impulsivity. Inattention refers to disorganization and difficulty in sustaining focus; hyperactivity manifests as excessive motor activity or talking activeness in inappropriate 


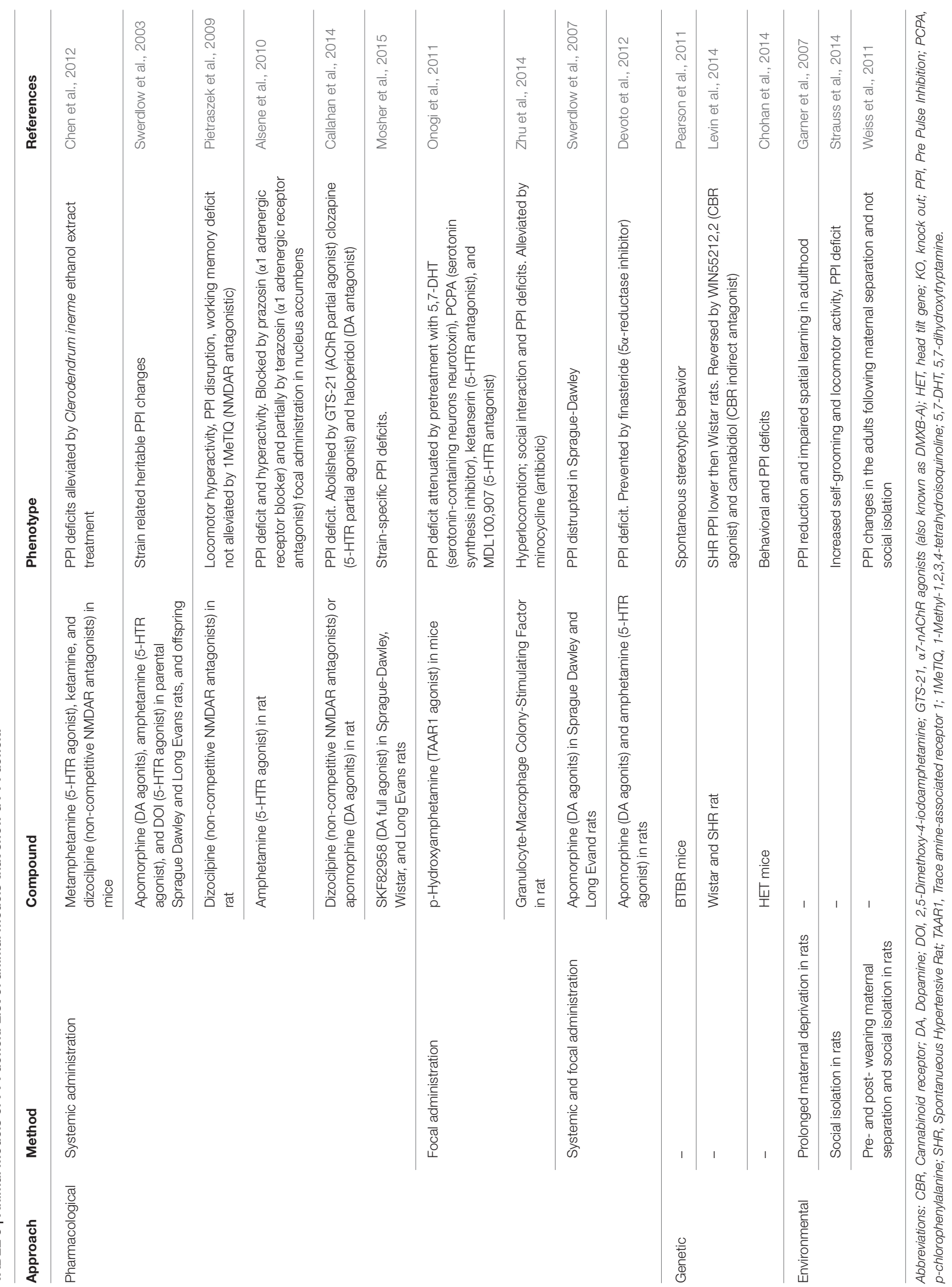




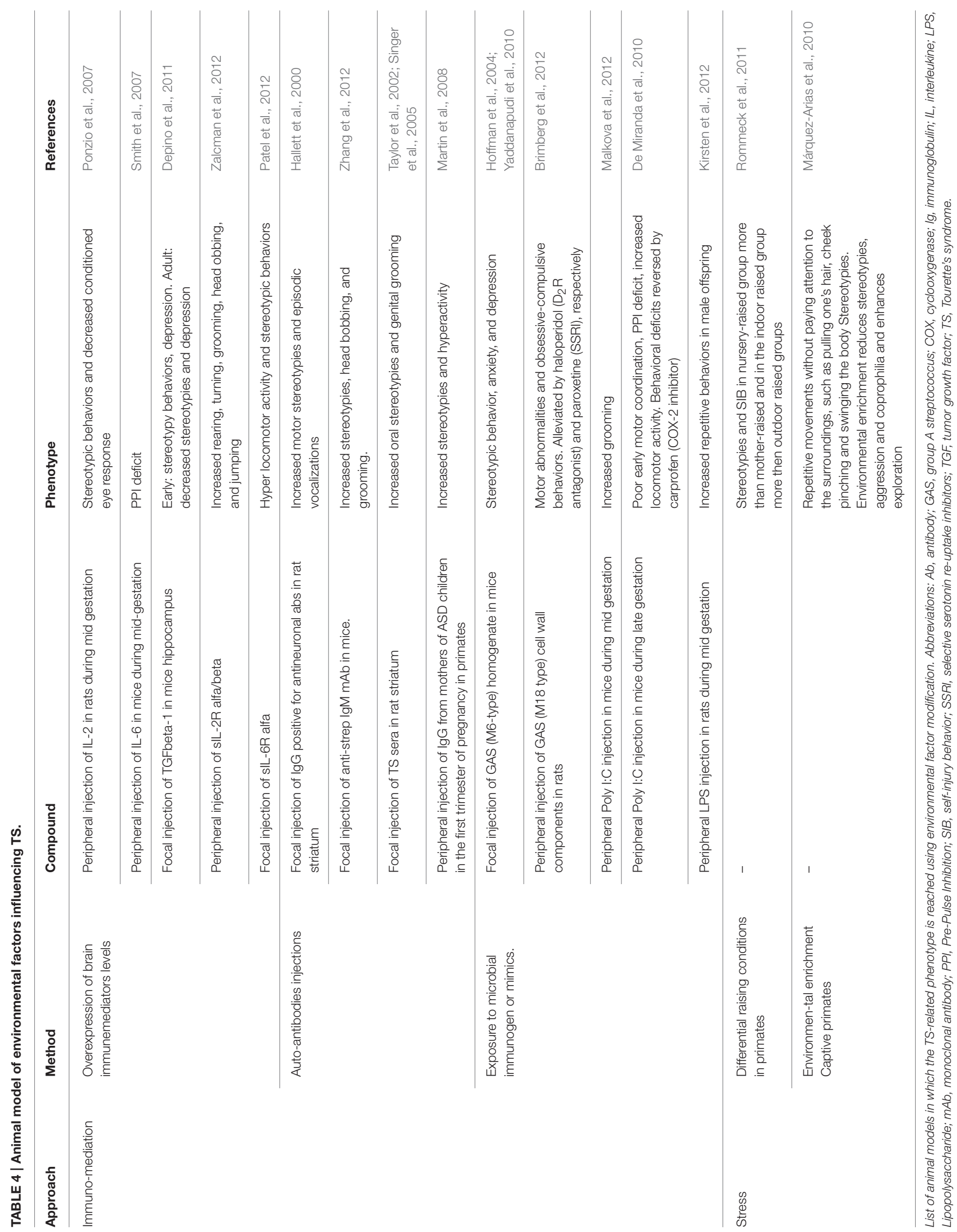


situations; impulsivity refers to the tendency to perform, without adequate forethought.

The cause of ADHD still remains elusive but it most likely results from a combination of cofactors that can be genetic, developmental, and/or environmental. The observation that the most effective drugs for ADHD treatment are psychostimulants (Sagvolden et al., 2005), implicates a role for catecholamines in the development of the disease. Indeed, the dopaminergic D1, D4, and D5 receptor genes, the $\alpha 2$-adrenoceptor gene, and both dopamine and norepinephrine transporters (DAT1, NET1) genes show polymorphisms in ADHD patients (Cook et al., 1995; Manor et al., 2004; Bobb et al., 2005; Park et al., 2005; Kickler et al., 2009). Serotonin has also been indicated to play a role in $\mathrm{ADHD}$, as suggested by polymorphisms in genes that encode the serotonin transporter and the serotonin $1 \mathrm{~B}$ receptor (Kent et al., 2002).

Since ADHD affects $60-80 \%$ of children with TS (Khalifa and Knorring, 2007), a common pathophysiological link between these two disorders seems evident. A debate is going on whether the two pathologies are independent (additive model), combined (interactive model), or a phenotype subgroup of one of the two major clinical forms (phenotype model) (Cavanna et al., 2009; Greimel et al., 2011; Schlander et al., 2011), however, there is increasing evidence for an additive model (Lebowitz et al., 2012; Roessner et al., 2007).

\section{Modeling ADHD}

Inattention, motor hyperactivity, and increased impulsivity are the three core features of ADHD. They have been differently modeled using (i) genetic manipulation, for instance in DAT-KO mice, coloboma mutant mice, nicotinic receptor mutant mice, human thyroid receptor expressing mice, GAT1-KO mice, ACC mice, and mutant tachinin-1 mice (Gainetdinov and Caron, 2000; Granon and Changeux, 2006; Siesser et al., 2006; Bruno et al., 2007; Yan et al., 2009; Zimmermann et al., 2014), (ii) selective breeding, as in SHR rats and Naples high excitability rats (Sadile et al., 1993; Sagvolden, 2000) (iii) insulting events during early developmental stages through 6-hydroxydopamine lesion and prenatal nicotine exposure (Stead et al., 2006; Schneider et al., 2011; Zhu et al., 2012; Freund et al., 2014) (iv) social isolation (Ouchi et al., 2013).

To validate these models, sustained attention deficits should be shown when stimuli are widely spaced in time, hyperactivity should be absent in novel situations and develop gradually over time and impulsivity should be sensitive to reinforcers (for review see Sagvolden et al., 2005).

SHR rats have been the most extensively used model of ADHD and feature all core aspects of this disorders. However, in SHR rats and in all previously listed ADHD models tic-like behaviors have not been documented.

Animal models of TS showing comorbid full ADHD spectrum have not been reported so far, but some validity for the single features were documented: hyperactivity was associated to specific bicuculline injections sites in the dorsal striatum and dorsal GPe of primates (Grabli et al., 2004; Worbe et al., 2009) and attention deficit occurred after injections in associative regions of the GPe (Grabli et al., 2004).

\section{OCD}

OCD is a neuropsychiatric disease that is frequently found as comorbidity in adult TS patients. It is a chronic disorder, which affects approximately $1-3 \%$ of the population (Pallanti et al., 2011).

According to DSM-5, obsessions, compulsions, or both, have to be present for an OCD diagnosis. Obsessions are defined as recurrent and persistent thoughts (e.g., fear of contamination), urges (e.g., need to wash hands), or images (e.g., of a violent or horrific scene) that are experienced as intrusive and unwanted, and cause marked anxiety and distress. The individual will try to suppress or to neutralize obsessions with some other thoughts or actions, for instance by performing a compulsion. Compulsions are defined as repetitive mental acts (e.g., counting) or behaviors (e.g., washing hands) performed in response to an obsession or according to rules that must be applied rigidly to a clearly excessive point when they become disruptive for daily living. OCD patients are able to recognize their obsessions and compulsions, but are unable to avoid them (Koran et al., 1996; Okasha et al., 2000).

The etiology of OCD is not completely understood.

Serotonin was the first neurotransmitter to be associated with OCD pathophysiology when selective serotonin re-uptake inhibitors (SSRIs) were shown to be efficacious in treating OCD (Barr et al., 1992). However, many patients do not respond to SSRIs treatment suggesting the additional involvement of other NTs such as dopamine (Carey et al., 2005; Taj et al., 2013), GABA (Simpson et al., 2012; Russo and Pietsch, 2013; Russo et al., 2014) and particularly glutamate (Arnold et al., 2006; Alonso et al., 2012; Porton et al., 2013). Growing evidence indicates the latter as a putative central player in OCD pathophysiology, strengthening the glutamate hypothesis of OCD and opening a new window for the development of novel treatment strategies (Coric et al., 2005; Grant et al., 2007; Bakhla et al., 2013).

Dopamine, GABA, and glutamate are commonly associated to CSTC circuit malfunction, implicating a role for this circuit in OCD pathophysiology (Stahl, 1988; Insel and Winslow, 1992; Graybiel and Rauch, 2000; Welch et al., 2007). Such alterations are also thought to be causative of tics, which $30 \%$ of OCD patients develop (Bloch et al., 2006; Pallanti et al., 2011). Tics and compulsions are now considered to be two different sides of the same coin that may be grouped under the general term of "ticlike" activities (Lombroso and Scahill, 2008; Worbe et al., 2010; Cath et al., 2011; Martino et al., 2013).

\section{Modeling OCD}

In animal models reported to have validity for OCD the presence of obsessions has been reasonably left aside and the focus was on the presence of behavioral compulsivity, intended as the performance of repetitive, and perseverating actions and stereotypies (for review see Alonso et al., 2015).

It is interesting to underline the existence of an analog to OCD in dogs: the Canine Compulsive Disorder (CCD), which leads to excessive tail chasing, light/shadow chasing, and flank sucking. These behaviors are attenuated with the same treatments used for OCD, indicating that its study may help elucidate the etiology of compulsive disorders (Ogata et al., 2013). 
Numerous validated approaches have been developed aiming to evaluate and quantify compulsive-like behaviors. Examples are the schedule-induced polydipsia (Woods et al., 1993), the marble burying test (Ichimaru et al., 1995), the signal attenuation test (Joel et al., 2005) the nest building test (Hoffman and Rueda Morales, 2012) and the nestlet shredding test (Angoa-Pérez et al., 2012). These models provide the greatest ease of use and do not require any pharmacological or genetic intervention but on the other hand they do not offer any pathophysiological information.

Based on the clinical evidence for an involvement of serotonin in OCD, OCD-like behaviors are induced in animals by treatments with serotonergic agonists 8-hydroxy-2-(di-npropylamino) tetralin (8-OH-DPAT) (Carli et al., 2006; Arora et al., 2013) and m-chlorophenylpiperazine (mCPP) (Kreiss et al., 2013), as well as with the serotonin releasing agent compound 48-80 (Wald et al., 2009). Mice lacking TPH2, the rate-limiting enzyme of serotonin synthesis in the brain, display highly repetitive and compulsive behaviors (Kane et al., 2012).

The glutamatergic hypothesis of OCD finds also a strong support in animal models. In mice lacking the AMPA receptor trafficking protein SAPAP3, glutamate signaling dysfunction is accompanied by compulsive grooming behavior (Welch et al., 2007; Wu et al., 2012).

Astrocyte-specific glutamate transporter (GLT1) inducible knockout mice exhibit OCD/TS-like behavioral spectrum, with marked increased self-injurious grooming behavior (Aida et al., 2015). Interestigly, this is the first hint of a role for non-neuronal cells in this brain disorder. Lastly, transmembrane protein Slitrk5 KO mice show OCD-like behavioral abnormalities that seem to be associated to a deficient corticostriatal neurotransmission (Abelson et al., 2005; Shmelkov et al., 2010). Slitrk5 belongs to the same family of Slitrk1, a protein associated to TS.

Dopamine, that has been largely associated to TS and ADHD, is supported by animal models findings to play a role in compulsive behaviors. The treatment with the DR2 agonist quinpirole in mice marks the expression of the behavioral repertoire and long-term exposure to this drug leads to hyperactivity in $\mathrm{A} / \mathrm{J}$ mice (De Haas et al., 2012). In rats, chronic administration of the same compound causes compulsive checking (Szechtman et al., 1998; Alkhatib et al., 2013).

In the D1CT-7 transgenic mouse, the modulation of the glutamatergic cortical output on the striatal circuits obtained through the chronic potentiation of cortical and limbic D1expressing neurons leads to the development not only of compulsive behaviors, but also of tics. This makes it the only model of comorbid tics and OCD proposed so far (Smicun et al., 1999; Nordstrom and Burton, 2002).

\section{CONCLUSIONS}

Animal models are gaining an important role in understanding TS pathophysiology and in investigating new treatment options. In the recent years numerous models have been developed, many of which summarize more than a single aspect of the syndrome.

Through animal models the idea of a major role for the striatum in tics generation, already suggested by imaging and post mortem studies, was importantly strengthened. In fact, independent approaches used to model TS succeeded in showing increased grooming and tic-like phenotype following striatal structural and functional alterations. This indicates the striatum as a research target worth investing more efforts.

Reproducing tics, the core feature of TS, is the actual greatest challenge for animal models. A TS diagnosis requires the coexistence of multiple motor and at least a vocal tic, but so far researchers focused on motor tics while the presence and cause of vocal tics has been poorly investigated and require further attention.

The difference between tics and other movement disorders can be detected in humans but it is subtler in animals that physiologically account a wide range of species-specific repetitive movements in their repertoire. In patients, tics have the peculiar features of being preceded by a PU, have a waxing and waning pattern and can be voluntarily repressed. These distinctive features of tics are difficult to observe in animals and result severely biased by the approach used. Stereotypies, which are fixed, prolonged, and rhythmic repetitive behaviors with an early onset and a fixed presentation pattern (DSM-5), can be confused with tics in animal models, though they are separated clinical entities. A discriminative method between these two motor phenotypes in animal models could increase face validity and help the development of more targeted therapeutic strategies. To achieve this point, a better understanding of the animals' behavioral spectrum along with a beter knowledge of tics' generating mechanisms are needed.

Finally, TS is classified as a neurodevelopmental syndrome, as it is typically diagnosed in childhood or adolescence, and tics show spontaneous and substantial reduction toward the end of the second decade of life in more than half of patients. However, so far, animal model research lacked the investigation of the way development affects the phenotype. Juvenile animal models could elucidate the impact of developmental mechanisms and importantly help the study of more effective and safer therapies for young patients.

\section{AUTHOR CONTRIBUTIONS}

FR and EN equally contributed to the design, drafting, writing and revising of the work. AL contributed to the design, drafting, and critical revision under a clinical point of view. $\mathrm{BH}$ and $\mathrm{TB}$ contributed to the drafting, critical revision under a pre-clinical point of view, and final approval of the work.

\section{FUNDING}

This work was supported by the European Commission Seventh Framework Programme (FP7-PEOPLE-2012-ITN), under the grant agreement $\mathrm{n}^{\circ} 316978$.

\section{ACKNOWLEDGMENTS}

We dedicate this work to our dear colleague and mentor AL who sadly passed away during the preparation of this manuscript. 


\section{REFERENCES}

Abelson, J. F., Kenneth, K. Y., O’Roak, B. J., Baek, D. Y., Stillman, A. A., Morgan, T. M., et al. (2005). Sequence Variants in SLITRK1 Are Associated with Tourette's Syndrome. Science 310, 317-320. doi: 10.1126/science.1116502

Aida, T., Yoshida, J., Nomura, M., Tanimura, A., Iino, Y., Soma, M., et al. (2015). Astroglial glutamate transporter deficiency increases synaptic excitability and leads to pathological repetitive behaviors in mice. Neuropsychopharmacology 40, 1569-1579. doi: 10.1038/npp.2015.26

Albin, R. L., and Mink, J. W. (2006). Recent advances in Tourette syndrome research. Trends Neurosci. 29, 175-182. doi: 10.1016/j.tins.2006.01.001

Alkhatib, A. H., Dvorkin-Gheva, A., and Szechtman, H. (2013). Quinpirole and 8-OH-DPAT induce compulsive checking behavior in male rats by acting on different functional parts of an OCD neurocircuit. Behav. Pharmacol. 24, 65-73. doi: 10.1097/FBP.0b013e32835d5b7a

Alonso, P., Gratacós, M., Segalàs, C., Escaramís, G., Real, E., Bayés, M., et al. (2012). Association between the NMDA Glutamate Receptor GRIN2B Gene and Obsessive-Compulsive Disorder. J. Psychiatry Neurosci. 37, 273-281. doi: 10.1503/jpn.110109

Alonso, P., López-Solà, C., Real, E., Segalàs, C., and Menchón, J. M. (2015). Animal models of obsessive-compulsive disorder: utility and limitations. Neuropsychiatr. Dis. Treat. 11, 1939-1955. doi: 10.2147/NDT.S62785

Alsene, K. M., Fallace, K., and Bakshi, V. P. (2010). Ventral striatal noradrenergic mechanisms contribute to sensorimotor gating deficits induced by amphetamine. Neuropsychopharmacology 35, 2346-2356. doi: 10.1038/npp.2010.106

Angoa-Pérez, M., Kane, M. J., Briggs, D. I., Sykes, C. E., Shah, M. M., Francescutti, D. M., et al. (2012). Genetic depletion of brain 5HT reveals a common molecular pathway mediating compulsivity and impulsivity. J. Neurochem. 121, 974-984. doi: 10.1111/j.1471-4159.2012.07739.x

Arnold, P. D., Sicard, T., Burroughs, E., Richter, M. A., and Kennedy, J. L. (2006). Glutamate transporter gene SLC1A1 associated with obsessive-compulsive disorder. Arch. Gen. Psychiatry 63, 769-776. doi: 10.1001/archpsyc.63.7.769

Arora, T., Bhowmik, M., Khanam, R., and Vohora, D. (2013). Oxcarbazepine and fluoxetine protect against mouse models of obsessive compulsive disorder through modulation of cortical serotonin and CREB pathway. Behav. Brain Res. 247, 146-152. doi: 10.1016/j.bbr.2013.02.038

Bakhla, A. K., Verma, V., Soren, S., Sarkhel, S., and Chaudhury, S. (2013). An openlabel trial of memantine in treatment-resistant obsessive-compulsive disorder. Ind. Psychiatry J. 22, 149-152. doi: 10.4103/0972-6748.132930

Barr, L. C., Goodman, W. K., Price, L. H., McDougle, C. J., and Charney, D. S. (1992). The serotonin hypothesis of obsessive compulsive disorder: implications of pharmacologic challenge studies. J. Clin. Psychiatry 53(Suppl.), $17-28$.

Berridge, K. C., Aldridge, J. W., Houchard, K. R., and Zhuang, X. (2005). Sequential super-stereotypy of an instinctive fixed action pattern in hyper-dopaminergic mutant mice: a model of obsessive compulsive disorder and Tourette's. BMC Biol. 3:4. doi: 10.1186/1741-7007-3-4

Bertelsen, B., Stefánsson, H., Rif Jensen, L., Melchior, L., Mol Debes, N., Groth, C., et al. (2015). Association of AADAC deletion and Gilles de La Tourette Syndrome in a large European Cohort. Biol. Psychiatry 79, 383-391. doi: 10.1016/j.biopsych.2015.08.027

Biermann-Ruben, K., Miller, A., Franzkowiak, S., Finis, J., Pollok, B., Wach, C., et al. (2012). Increased sensory feedback in Tourette syndrome. Neuroimage 63, 119-125. doi: 10.1016/j.neuroimage.2012.06.059

Bloch, M. H., Sukhodolsky, D. G., Leckman, J. F., and Schultz, R. T. (2006). Fine-motor skill deficits in childhood predict adulthood tic severity and global psychosocial functioning in Tourette's syndrome. J. Child Psychol. Psychiatry 47, 551-559. doi: 10.1111/j.1469-7610.2005.01561.x

Bobb, A. J., Addington, A. M., Sidransky, E., Gornick, M. C., Lerch, J. P., Greenstein, D. K., et al. (2005). Support for association between ADHD and two candidate genes: NET1 and DRD1. Am. J. Med. Genet. B Neuropsychiatr. Genet. 134B, 67-72. doi: 10.1002/ajmg.b.30142

Braff, D. L., Geyer, M. A., and Swerdlow, N. R. (2001). Human studies of prepulse inhibition of startle: normal subjects, patient groups, and pharmacological studies. Psychopharmacology 156, 234-258. doi: 10.1007/s002130100810

Brimberg, L., Benhar, I., Mascaro-Blanco, A., Alvarez, K., Lotan, D., Winter, C., et al. (2012). Behavioral, pharmacological, and immunological abnormalities after streptococcal exposure: a novel rat model of Sydenham Chorea and related neuropsychiatric disorders. Neuropsychopharmacology 37, 2076-2087. doi: 10.1038/npp.2012.56

Bronfeld, M., Yael, D., Belelovsky, K., and Bar-Gad, I. (2013). Motor tics evoked by striatal disinhibition in the rat. Front. Syst. Neurosci. 7:50. doi: $10.3389 /$ fnsys. 2013.00050

Bruno, K. J., Freet, C. S., Twining, R. C., Egami, K., Grigson, P. S., and Hess, E. J. (2007). Abnormal latent inhibition and impulsivity in coloboma mice, a model of ADHD. Neurobiol. Dis. 25, 206-216. doi: 10.1016/j.nbd.2006.09.009

Bruun, R. D. (1984). Gilles de La Tourette's syndrome. An overview of clinical experience. J. Am. Acad. Child Psychiatry 23, 126-133. doi: 10.1097/00004583198403000-00002

Buse, J., Schoenefeld, K., Münchau, A., and Roessner, V. (2013). Neuromodulation in Tourette syndrome: dopamine and beyond. Neurosci. Biobehav. Rev. 37, 1069-1084. doi: 10.1016/j.neubiorev.2012.10.004

Callahan, P. M., Terry, A. V., and Tehim, A. (2014). Effects of the nicotinic a7 receptor partial agonist GTS-21 on NMDA-glutamatergic receptor related deficits in sensorimotor gating and recognition memory in rats. Psychopharmacology 231, 3695-3706. doi: 10.1007/s00213-014-3509-2

Campbell, K. M., Veldman, M. B., McGrath, M. J., and Burton, F. H. (2000). TS+OCD-like neuropotentiated mice are supersensitive to seizure induction. Neuroreport 11, 2335-2338. doi: 10.1097/00001756-200007140-00053

Carey, P. D., Vythilingum, B., Seedat, S., Muller, J. E., van Ameringen, M., and Stein, D. J. (2005). Quetiapine augmentation of SRIs in treatment refractory obsessive-compulsive disorder: a double-blind, randomised, placebo-controlled study [ISRCTN83050762]. BMC Psychiatry 5:5 doi: 10.1186/1471-244X-5-5

Carli, M., Baviera, M., Invernizzi, R. W., and Balducci, C. (2006). Dissociable contribution of 5-HT1A and 5-HT2A receptors in the medial prefrontal cortex to different aspects of executive control such as impulsivity and compulsive perseveration in rats. Neuropsychopharmacology 31, 757-767. doi: 10.1038/sj.npp.1300893

Castellan Baldan, L., Williams, K. A., Gallezot, J. D., Pogorelov, V., Rapanelli, M., Crowley, M., et al. (2014). Histidine decarboxylase deficiency causes Tourette syndrome: parallel findings in humans and mice. Neuron 81, 77-90. doi: 10.1016/j.neuron.2013.10.052

Castellanos, F. X., Fine, E. J., Kaysen, D., Marsh, W. L., Rapoport, J. L., and Hallett, M. (1996). Sensorimotor gating in boys with Tourette's syndrome and ADHD: preliminary results. Biol. Psychiatry 39, 33-41. doi: 10.1016/00063223(95)00101-8

Cath, D. C., Hedderly, T., Ludolph, A. G., Stern, J. S., Murphy, T., Hartmann, A., et al. (2011). European clinical guidelines for Tourette syndrome and other tic disorders. Part I: Assessment. Eur. Child Adolesc. Psychiatry 20, 155-171. doi: 10.1007/s00787-011-0164-6

Cavanna, A. E., Servo, S., Monaco, F., and Robertson, M. M. (2009). The behavioral spectrum of Gilles de La Tourette syndrome. J. Neuropsychiatry Clin. Neurosci. 21, 13-23. doi: 10.1176/jnp.2009.21.1.13

Ceci, C., Proietti Onori, M., Macrì, S., and Laviola, G. (2015). Interaction between the endocannabinoid and serotonergic system in the exhibition of head twitch response in four mouse strains. Neurotox. Res. 27, 275-283. doi: 10.1007/s12640-014-9510-z

Chao, T. K., Hu, J., and Pringsheim, T. (2014). Prenatal risk factors for Tourette syndrome: a systematic review. BMC Pregnancy Childbirth 14:53. doi: 10.1186/1471-2393-14-53

Chen, H.-L., Lee, H.-J., Huang, W.-J., Chou, J.-F., Fan, P.-C., Du, J.-C., et al. (2012). Clerodendrum inerme leaf extract alleviates animal behaviors, hyperlocomotion, and prepulse inhibition disruptions, mimicking Tourette syndrome and Schizophrenia. Evid. Based Complement. Alternat. Med. 2012:284301. doi: 10.1155/2012/284301

Chohan, T. W., Boucher, A. A., Spencer, J. R., Kassem, M. S., Hamdi, A. A., Karl, T., et al. (2014). Partial genetic deletion of neuregulin 1 modulates the effects of stress on sensorimotor gating, dendritic morphology, and HPA axis activity in adolescent mice. Schizophr. Bull. 40, 1272-1284. doi: 10.1093/schbul/sbt193

Cohen, A. J., and Leckman, J. F. (1992). Sensory phenomena associated with Gilles de La Tourette's syndrome. J. Clin. Psychiatry 53, 319-23.

Conelea, C. A., and Woods, D. W. (2008). Examining the impact of distraction on tic suppression in children and adolescents with Tourette syndrome. Behav. Res. Ther. 46, 1193-1200. doi: 10.1016/j.brat.2008.07.005 
Cook, E. H., Stein, M. A., Krasowski, M. D., Cox, N. J., Olkon, D. M., Kieffer, J. E., et al. (1995). Association of attention-deficit disorder and the dopamine transporter gene. Am. J. Hum. Genet. 56, 993-998.

Corbett, B. A., Mendoza, S. P., Baym, C. L., Bunge, S. A., and Levine, S. (2008). Examining cortisol rhythmicity and responsivity to stress in children with Tourette syndrome. Psychoneuroendocrinology 33, 810-820. doi: 10.1016/j.psyneuen.2008.03.014

Coric, V., Taskiran, S., Pittenger, C., Wasylink, S., Mathalon, D. H., Valentine, G., et al. (2005). Riluzole augmentation in treatment-resistant obsessivecompulsive disorder: an open-label trial. Biol. Psychiatry 58, 424-428. doi: 10.1016/j.biopsych.2005.04.043

Crane, J., Fagerness, J., Osiecki, L., Gunnell, B., Stewart, S. E., Pauls, D. L., et al. (2011). Family-based genetic association study of DLGAP3 in Tourette Syndrome. Am. J. Med. Genet. B Neuropsychiatr. Genet. 156B, 108-114. doi: 10.1002/ajmg.b.31134

De Haas, R., Seddik, A., Oppelaar, H., Westenberg, H. G. M., and Kas, M. J. H. (2012). Marked inbred mouse strain difference in the expression of quinpirole induced compulsive like behavior based on behavioral pattern analysis. Eur. Neuropsychopharmacol. 22, 657-663. doi: 10.1016/j.euroneuro.2012.01.003

De Miranda, J., Yaddanapudi, K., Hornig, M., Villar, G., Serge, R., and Lipkin, W. I. (2010). Induction of toll-like receptor 3-mediated immunity during gestation inhibits cortical neurogenesis and causes behavioral disturbances. MBio 1:e00176-10. doi: 10.1128/mbio.00176-10

Depino, A. M., Lucchina, L., and Pitossi, F. (2011). Early and adult hippocampal TGF- $\beta 1$ overexpression have opposite effects on behavior. Brain Behav. Immun. 25, 1582-1591. doi: 10.1016/j.bbi.2011.05.007

Devoto, P., Frau, R., Bini, V., Pillolla, G., Saba, P., Flore, G., et al. (2012). Inhibition of $5 \alpha$-reductase in the nucleus accumbens counters sensorimotor gating deficits induced by dopaminergic activation. Psychoneuroendocrinology 37, 1630-1645. doi: 10.1016/j.psyneuen.2011.09.018

Fantegrossi, W. E., Harrington, A. W., Eckler, J. R., Arshad, S., Rabin, R. A., Winter, J. C., et al. (2005). Hallucinogen-like Actions of 2,5-Dimethoxy-4-(n)Propylthiophenethylamine (2C-T-7) in mice and rats. Psychopharmacology 181, 496-503. doi: 10.1007/s00213-005-0009-4

Fantegrossi, W. E., Harrington, A. W., Kiessel, C. L., Eckler, J. R., Rabin, R. A., Winter, J. C., et al. (2006). Hallucinogen-like Actions of 5-MethoxyN,N-Diisopropyltryptamine in mice and rats. Pharmacol. Biochem. Behav. 83, 122-129. doi: 10.1016/j.pbb.2005.12.015

Frank, M., and Cavanna, A. E. (2013). Behavioural treatments for tourette syndrome: an evidence-based review. Behav. Neurol. 27, 105-117. doi: $10.1155 / 2013 / 134863$

Freund, N., MacGillivilray, H. T., Thompson, B. S., Lukkes, J. L., Stanis, J. J., Brenhouse, H. C., et al. (2014). Sex-dependent changes in ADHD-like behaviors in juvenile rats following cortical dopamine depletion. Behav. Brain Res. 270, 357-363. doi: 10.1016/j.bbr.2014.05.024

Gainetdinov, R. R., and Caron, M. G. (2000). An animal model of attention deficit hyperactivity disorder. Mol. Med. Today 6, 43-44. doi: 10.1016/S13574310(99)01616-0

Ganos, C., Kahl, U., Schunke, O., Kühn, S., Haggard, P., Gerloff, C., et al. (2012). Are premonitory urges a prerequisite of tic inhibition in Gilles de La Tourette syndrome? J. Neurol. Neurosurg. Psychiatr. 83, 975-978. doi: 10.1136/jnnp2012-303033

Garner, B., Wood, S. J., Pantelis, C., and van den Buuse, M. (2007). Early maternal deprivation reduces prepulse inhibition and impairs spatial learning ability in adulthood: no further effect of post-pubertal chronic corticosterone treatment. Behav. Brain Res. 176, 323-332. doi: 10.1016/j.bbr.2006. 10.020

Garner, J. P., and Mason, G. J. (2002). Evidence for a relationship between cage stereotypies and behavioural disinhibition in laboratory rodents. Behav. Brain Res. 136, 83-92. doi: 10.1016/S0166-4328(02)00111-0

Godar, S. C., Mosher, L. J., Strathman, H. J., Gochi, A. M., Jones, C. M., Fowler, S. C., et al. (2015). The D1CT-7 mouse model of Tourette syndrome displays sensorimotor gating deficits in response to spatial confinement. Br. J. Pharmacol. doi: 10.1111/bph.13243. [Epub ahead of print].

Grabli, D., McCairn, K., Hirsch, E. C., Agid, Y., Féger, J., François, C., et al. (2004). Behavioural disorders induced by external globus pallidus dysfunction in primates: I. Behavioural study. Brain 127(Pt 9), 2039-2054. doi: 10.1093/ brain/awh 220
Granon, S., and Changeux, J.-P. (2006). Attention-deficit/hyperactivity disorder: a plausible mouse model? Acta Paediatr. 95, 645-649. doi: 10.1080/08035250600719747

Grant, P., Lougee, L., Hirschtritt, M., and Swedo, S. E. (2007). An open-label trial of riluzole, a glutamate antagonist, in children with treatment-resistant obsessive-compulsive disorder. J. Child Adolesc. Psychopharmacol. 17, 761-67. doi: 10.1089/cap.2007.0021

Graybiel, A. M., and Rauch, S. L. (2000). Toward a neurobiology of obsessivecompulsive disorder. Neuron 28, 343-347. doi: 10.1016/S0896-6273(00) 00113-6

Greimel, E., Schulte-Rüther, M., Kamp-Becker, I., Remschmidt, H., HerpertzDahlmann, B., and Konrad, K. (2011). Self-report and parental report of empathy in adolescents with autism. Z. Kinder Jugendpsychiatr. Psychother. 39, 113-121. doi: 10.1024/1422-4917/a000097

Halberstadt, A. L., and Geyer, M. A. (2014). Effects of the Hallucinogen 2,5-Dimethoxy-4-Iodophenethylamine (2C-I) and Superpotent N-Benzyl derivatives on the head twitch response. Neuropharmacology 77, 200-207. doi: 10.1016/j.neuropharm.2013.08.025

Hall, F. S. (1998). Social deprivation of neonatal, adolescent, and adult rats has distinct neurochemical and behavioral consequences. Critic. Rev. Neurobiol. 12, 129-162. doi: 10.1615/CritRevNeurobiol.v12.i1-2.50

Hallett, J. J., Harling-Berg, C. J., Knopf, P. M., Stopa, E. G., and Kiessling, L. S. (2000). Anti-striatal antibodies in Tourette syndrome cause neuronal dysfunction. J. Neuroimmunol. 111, 195-202. doi: 10.1016/S0165-5728(00)00320-9

Hayslett, R. L., and Tizabi, Y. (2003). Effects of Donepezil on DOI-induced head twitch response in mice: implications for Tourette syndrome. Pharmacol. Biochem. Behav. 76, 409-415. doi: 10.1016/j.pbb.2003.08.015

Hoekstra, P. J., and Minderaa, R. B. (2005). Tic disorders and obsessive-compulsive disorder: is autoimmunity involved? Int. Rev. Psychiatry 17, 497-502. doi: 10.1080/02646830500382003

Hoffman, K. L., Hornig, M., Yaddanapudi, K., Jabado, O., and Lipkin, W. I. (2004). A murine model for neuropsychiatric disorders associated with group A beta-hemolytic streptococcal infection. J. Neurosci. 24, 1780-1791. doi: 10.1523/JNEUROSCI.0887-03.2004

Hoffman, K. L., and Rueda Morales, R. I. (2012). D1 and D2 dopamine receptor antagonists decrease behavioral Bout duration, without altering the Bout's repeated behavioral components, in a naturalistic model of repetitive and compulsive behavior. Behav. Brain Res. 230, 1-10. doi: 10.1016/j.bbr.2012.01.041

Huang, W. J., Lee, H. J., Chen, H. L., Fan, P. C., Ku, Y. L., and Chiou, L. C. (2015). Hispidulin, a constituent of clerodendrum inerme that remitted motor tics, alleviated methamphetamine-induced hyperlocomotion without motor impairment in mice. J. Ethnopharmacol. 166, 18-22. doi: 10.1016/j.jep.2015.03.001

Hyde, T. M., Aaronson, B. A., Randolph, C., Rickler, K. C., and Weinberger, D. R. (1992). Relationship of birth weight to the phenotypic expression of Gilles de La Tourette's syndrome in monozygotic twins. Neurology 42, 652-658. doi: 10.1212/WNL.42.3.652

Ichimaru, Y., Egawa, T., and Sawa, A. (1995). 5-HT1A-receptor subtype mediates the effect of fluvoxamine, a selective serotonin reuptake inhibitor, on marbleburying behavior in mice. Jpn. J. Pharmacol. 68, 65-70. doi: 10.1254/jjp.68.65

Insel, T. R., and Winslow, J. T. (1992). Neurobiology of obsessive compulsive disorder. Psychiatr. Clin. North Am. 15, 813-824. doi: 10.1097/00004850199206001-00008

Joel, D., Doljansky, J., and Schiller, D. (2005). 'Compulsive' lever pressing in rats is enhanced following lesions to the orbital cortex, but not to the basolateral nucleus of the amygdala or to the dorsal medial prefrontal cortex. Eur. J. Neurosci. 21, 2252-2262. doi: 10.1111/j.1460-9568.2005.04042.x

Kane, M. J., Angoa-Peréz, M., Briggs, D. I., Sykes, C. E., Francescutti, D. M., Rosenberg, D. R., et al. (2012). Mice genetically depleted of brain serotonin display social impairments, communication deficits and repetitive behaviors: possible relevance to autism. PLoS ONE 7:e48975. doi: 10.1371/journal.pone.0048975

Kataoka, Y., Kalanithi, P. S., Grantz, H., Schwartz, M. L., Saper, C., Leckman, J. F., et al. (2010). Decreased number of parvalbumin and cholinergic interneurons in the striatum of individuals with Tourette syndrome. J. Comp. Neurol. 518, 277-291. doi: 10.1002/cne.22206 
Katayama, K., Yamada, K., Ornthanalai, V. G., Inoue, T., Ota, M., Murphy, N. P., et al. (2010). Slitrk1-deficient mice display elevated anxiety-like behavior and noradrenergic abnormalities. Mol. Psychiatry 15, 177-184. doi: 10.1038/mp.2008.97

Kent, L., Doerry, U., Hardy, E., Parmar, R., Gingell, K., Hawi, Z., et al. (2002). Evidence that variation at the serotonin transporter gene influences susceptibility to Attention Deficit Hyperactivity Disorder (ADHD): analysis and pooled analysis. Mol. Psychiatry 7, 908-912. doi: 10.1038/sj.mp.4001100

Khalifa, N., and Knorring, A.-L. (2007). Tourette syndrome and other tic disorders in a total population of children: clinical assessment and background. Acta Paediatr. 94, 1608-1614. doi: 10.1111/j.1651-2227.2005.tb01837.x

Kickler, N., Lacombe, E., Chassain, C., Durif, F., Krainik, A., Farion, R., et al. (2009). Assessment of metabolic changes in the striatum of a rat model of parkinsonism: an in vivo $1 \mathrm{H}$ MRS study. NMR Biomed. 22, 207-212. doi: 10.1002/nbm.1305

Kirkman, N. J., Libbey, J. E., Sweeten, T. L., Coon, H. H., Miller, J. N., Stevenson, E. K., et al. (2008). How relevant are GFAP autoantibodies in autism and Tourette syndrome? J. Autism Dev. Disorders 38, 333-341. doi: 10.1007/s10803-0070398-9

Kirsten, T. B., Chaves-Kirsten, G. P., Chaible, L. M., Silva, A. C., Martins, D. O., Britto, L. R., et al. (2012). Hypoactivity of the central dopaminergic system and autistic-like behavior induced by a single early prenatal exposure to lipopolysaccharide. J. Neurosci. Res. 90, 1903-1912. doi: 10.1002/jnr.23089

Kompoliti, K., and Goetz, C. G. (1998). Hyperkinetic movement disorders misdiagnosed as tics in Gilles de la Tourette syndrome. Mov. Disord. 13, 477-480. doi: 10.1002/mds.870130317

Koran, L. M., Thienemann, M. L., and Davenport, R. (1996). Quality of life for patients with obsessive-compulsive disorder. Am. J. Psychiatry 153, 783-788. doi: 10.1176/ajp.153.6.783

Krause, D., Matz, J., Weidinger, E., Wagner, J., Wildenauer, A., Obermeier, M., et al. (2010). Association between intracellular infectious agents and Tourette's syndrome. Eur. Archiv. Psychiatry Clin. Neurosci. 260, 359-363. doi: 10.1007/s00406-009-0084-3

Kreiss, D. S., Coffman, C. F., Fiacco, N. R., Granger, J. C., Helton, B. M., Jackson, J. C., et al. (2013). Ritualistic chewing behavior induced by $\mathrm{mCPP}$ in the rat is an animal model of obsessive compulsive disorder. Pharmacol. Biochem. Behav. 104, 119-124. doi: 10.1016/j.pbb.2013.01.006

Kurlan, R. (2004). The PANDAS hypothesis: losing its bite? Mov. Disord. 19, 371-374. doi: 10.1002/mds.20107

Lebowitz, E. R., Motlagh, M. G., Katsovich, L., King, R. A., Lombroso, P. J., Grantz, H., et al. (2012). Tourette syndrome in youth with and without obsessive compulsive disorder and attention deficit hyperactivity disorder. Eur. Child Adolesc. Psychiatry 21, 451-57. doi: 10.1007/s00787-012-0278-5

Leckman, J. F., Walker, D. E., and Cohen, D. J. (1993). Premonitory urges in Tourette's syndrome. Am. J. Psychiatry 150, 98-102. doi: 10.1176/ajp.150.1.98

Lennington, J. B., Coppola, G., Kataoka-Sasaki, Y., Fernandez, T. V., Palejev, D., Li, Y., et al. (2014). Transcriptome analysis of the human striatum in Tourette syndrome. Biol. Psychiatry 79, 372-382. doi: 10.1016/j.biopsych.2014.07.018

Levin, R., Peres, F. F., Almeida, V., Calzavara, M. B., Zuardi, A. W., Hallak, J. E. C., et al. (2014). Effects of cannabinoid drugs on the deficit of prepulse inhibition of startle in an animal model of Schizophrenia: the SHR strain. Front. Pharmacol. 5:10. doi: 10.3389/fphar.2014.00010

Lin, H., Katsovich, L., Ghebremichael, M., Findley, D. B., Grantz, H., Lombroso, P. J., et al. (2007). Psychosocial stress predicts future symptom severities in children and adolescents with Tourette syndrome and/or obsessive-compulsive disorder. J. Child Psychol. Psychiatry 48, 157-166. doi: 10.1111/j.14697610.2006.01687.x

Lombroso, P. J., Mack, G., Scahill, L., King, R. A., and Leckman, J. F. (1991). Exacerbation of Gilles de La Tourette's syndrome associated with thermal stress: a family study. Neurology 41, 1984-1987. doi: 10.1212/wnl.41.12.1984

Lombroso, P. J., and Scahill, L. (2008). Tourette syndrome and obsessive-compulsive disorder. Brain Dev. 30, 231-237. doi: 10.1016/j.braindev.2007.09.001

Lv, H., Li, A., Ma, H., Liu, F., and Xu, H. (2009). Effects of Ningdong Granule on the dopamine system of Tourette's syndrome rat models. J. Ethnopharmacol. 124, 488-492. doi: 10.1016/j.jep.2009.05.015

Malkova, N. V., Yu, C. Z., Hsiao, E. Y., Moore, M. J., and Patterson, P. H. (2012). Maternal immune activation yields offspring displaying mouse versions of the three core symptoms of autism. Brain Behav. Immun. 26, 607-616. doi: 10.1016/j.bbi.2012.01.011

Manor, I., Corbex, M., Eisenberg, J., Gritsenkso, I., Bachner-Melman, R., Tyano, S., et al. (2004). Association of the dopamine D5 receptor with Attention Deficit Hyperactivity Disorder (ADHD) and scores on a continuous performance test (TOVA). Am. J. Med. Genet. 127B, 73-77. doi: 10.1002/ajmg.b. 30020

Márquez-Arias, A., Santillán-Doherty, A. M., Arenas-Rosas, R. V., Gasca-Matías, M. P., and Muñoz-Delgado, J. (2010). Environmental enrichment for captive stumptail Macaques (Macaca Arctoides). J. Med. Primatol. 39, 32-40. doi: 10.1111/j.1600-0684.2009.00392.x

Martin, L. A., Ashwood, P., Braunschweig, D., Cabanlit, M., Van de Water, J., and Amaral, D. G. (2008). Stereotypies and hyperactivity in Rhesus monkeys exposed to IgG from mothers of children with autism. Brain Behav. Immun. 22, 806-816. doi: 10.1016/j.bbi.2007.12.007

Martino, D., Macerollo, A., and Leckman, J. F. (2013). Neuroendocrine aspects of Tourette syndrome. Int. Rev. Neurobiol. 112, 239-279. doi: $10.1093 / \mathrm{med} / 9780199796267.001 .0001$

Mathews, C. A., Bimson, B., Lowe, T. L., Herrera, L. D., Budman, C. L., Erenberg, G., et al. (2006). Association between maternal smoking and increased symptom severity in Tourette's syndrome. Am. J. Psychiatry 163, 1066-1073. doi: 10.1176/ajp.2006.163.6.1066

McCairn, K. W., Iriki, A., and Isoda, M. (2013). Global dysrhythmia of cerebrobasal ganglia-cerebellar networks underlies motor tics following striatal disinhibition. J. Neurosci. 33, 697-708. doi: 10.1523/jneurosci.4018-12.2013

McCairn, K. W., Bronfeld, M., Belelovsky, K., and, Bar-Gad, I. (2009). The neurophysiological correlates of motor tics following focal striatal disinhibition. Brain 132(Pt 8), 2125-2138. doi: 10.1093/brain/awp142

McGrath, M. J., Campbell, K. M., Parks, C. R., and Burton, F. H. (2000). Glutamatergic drugs exacerbate symptomatic behavior in a transgenic model of comorbid Tourette's syndrome and obsessive-compulsive disorder. Brain Res. 877, 23-30. doi: 10.1016/S0006-8993(00)02646-9

McNamara, R. K., Logue, A., Stanford, K., Xu, M., Zhang, J., and Richtand, N. M. (2006). Dose-response analysis of locomotor activity and stereotypy in dopamine D3 receptor mutant mice following acute amphetamine. Synapse 60, 399-405. doi: 10.1002/syn.20315

Mosher, L. J., Frau, R., Pardu, A., Pes, R., Devoto, P., and Bortolato, M. (2015). Selective activation of D1 dopamine receptors impairs sensorimotor gating in long-evans rats. Br. J. Pharmacol. doi: 10.1111/bph.13232. [Epub ahead of print].

Motlagh, M. G., Katsovich, L., Thompson, N., Lin, H., Kim, Y. S., Scahill, L., et al. (2010). Severe psychosocial stress and heavy cigarette smoking during pregnancy: an examination of the pre- and perinatal risk factors associated with ADHD and Tourette syndrome. Eur. Child Adolesc. Psychiatry 19, 755-764. doi: 10.1007/s00787-010-0115-7

Nelson, D. A. (1993). Tourette's and stress. Neurology 43, 237-239. doi: 10.1212/WNL.43.1_Part_1.237-b

Nordstrom, E. J., Bittner, K. C., McGrath, M. J., Parks, C. R. III, and Burton, F. H. (2015). 'Hyperglutamatergic Cortico-Striato-Thalamo-Cortical Circuit' breaker drugs alleviate tics in a transgenic circuit model of Tourette's syndrome. Brain Res. 1629, 38-53. doi: 10.1016/j.brainres.2015.09.032

Nordstrom, E. J., and Burton, F. H. (2002). A transgenic model of comorbid Tourette's syndrome and obsessive-compulsive disorder circuitry. Mol. Psychiatry 7, 617-625. doi: 10.1038/sj.mp.4001144

Obeso, J. A., and Lanciego, J. L. (2011). Past, present, and future of the pathophysiological model of the Basal Ganglia. Front. Neuroanat. 5:39. doi: 10.3389/fnana.2011.00039

Ogata, N., Gillis, T. E., Liu, X., Cunningham, S. M., Lowen, S. B., Adams, B. L., et al. (2013). Brain structural abnormalities in doberman pinschers with canine compulsive disorder. Prog. Neuro Psychopharmacol. Biol. Psychiatry 45, 1-6. doi: 10.1016/j.pnpbp.2013.04.002

Okasha, A., Lotaief, F., Ashour, A. M., el Mahalawy, N., Seif el Dawla, A., and el-Kholy, G. (2000). The prevalence of obsessive compulsive symptoms in a sample of Egyptian psychiatric patients. L'Encéphale 26, 1-10.

Onogi, H., Nakagawasai, O., Sato, A., Mitazaki, S., Nakaya, K., Watanabe, K., et al. (2011). P-Hydroxyamphetamine causes prepulse inhibition disruption in mice: contribution of serotonin neurotransmission. Behav. Brain Res. 224, 159-165. doi: 10.1016/j.bbr.2011.06.002 
Ouchi, H., Ono, K., Murakami, Y., and Matsumoto, K. (2013). Social isolation induces deficit of latent learning performance in mice: a putative animal model of attention deficit/hyperactivity disorder. Behav. Brain Res. 238, 146-153. doi: 10.1016/j.bbr.2012.10.029

Oyungu, E., Kioy, P. G., and Patel, N. B. (2007). Effect of Catha Edulis (khat) on behaviour and its potential to induce seizures in Sprague Dawley rats. East Afr. Med. J. 84, 219-225.

Pallanti, S., Grassi, G., Sarrecchia, E. D., Cantisani, A., and Pellegrini, M. (2011). Obsessive-compulsive disorder comorbidity: clinical assessment and therapeutic implications. Front. Psychiatry 2:70. doi: 10.3389/fpsyt.2011.00070

Park, L., Nigg, J. T., Waldman, I. D., Nummy, K. A., Huang-Pollock, C., Rappley, M., et al. (2005). Association and linkage of alpha-2A adrenergic receptor gene polymorphisms with childhood ADHD. Mol. Psychiatry 10, 572-580. doi: 10.1038/sj.mp.4001605

Patel, A., Zhu, Y., Kuzhikandathil, E. V., Banks, W. A., Siegel, A., and Zalcman, S. S. (2012). Soluble Interleukin-6 receptor induces motor stereotypies and co-localizes with gp130 in regions linked to cortico-striato-thalamo-cortical circuits. PLoS ONE 7:e41623. doi: 10.1371/journal.pone.0041623

Pauls, D. L. (2003). An update on the genetics of Gilles de La Tourette syndrome. J. Psychosomat. Res. 55, 7-12. doi: 10.1016/S0022-3999(02)00586-X

Pauls, D. L., Raymond, C. L., Stevenson, J. M., and Leckman, J. F. (1991). A family study of Gilles de La Tourette syndrome. Am. J. Hum. Genet. 48, 154-163.

Pearson, B. L., Pobbe, R. L., Defensor, E. B., Oasay, L., Bolivar, V. J., Blanchard, D. C., et al. (2011). Motor and cognitive stereotypies in the BTBR $T+t f / J$ mouse model of autism. Genes Brain Behav. 10, 228-235. doi: 10.1111/j.1601183X.2010.00659.x

Peterson, B. S., Skudlarski, P., Anderson, A. W., Zhang, H., Gatenby, J. C., Lacadie, C. M., et al. (1998). A functional magnetic resonance imaging study of tic suppression in Tourette syndrome. Archiv. Gen. Psychiatry 55, 326-333. doi: 10.1001/archpsyc.55.4.326

Peterson, B. S., Thomas, P., Kane, M. J., Scahill, L., Zhang, H., Bronen, R., et al. (2003). Basal Ganglia volumes in patients with Gilles de La Tourette syndrome. Archiv. Gen. Psychiatry 60, 415-424. doi: 10.1001/archpsyc.60.4.415

Pietraszek, M., Michaluk, J., Romańska, I., Wasik, A., Gołembiowska, K., and Antkiewicz-Michaluk, L. (2009). 1-Methyl-1,2,3,4-tetrahydroisoquinoline antagonizes a rise in brain dopamine metabolism, glutamate release in frontal cortex and locomotor hyperactivity produced by MK- 801 but not the disruptions of prepulse inhibition, and impairment of working memory in rat. Neurotoxic. Res. 16, 390-407. doi: 10.1007/s12640-009-9097-y

Pogorelov, V., Xu, M., Smith, H. R., Buchanan, G. F., and Pittenger, C. (2015). Corticostriatal interactions in the generation of tic-like behaviors after local striatal disinhibition. Exp. Neurol. 265, 122-128. doi: 10.1016/j.expneurol.2015.01.001

Pogorelov, V. M., Rodriguiz, R. M., Insco, M. L., Caron, M. G., and Wetsel, W. C. (2005). Novelty seeking and stereotypic activation of behavior in mice with disruption of the Datl gene. Neuropsychopharmacology 30, 1818-1831. doi: 10.1038/sj.npp.1300724

Polanczyk, G., and Rohde, L. A. (2007). Epidemiology of attentiondeficit/hyperactivity disorder across the lifespan. Curr. Opin. Psychiatry 20, 386-392. doi: 10.1097/YCO.0b013e3281568d7a

Ponzio, N. M., Servatius, R., Beck, K., Marzouk, A., and Kreider, T. (2007). Cytokine levels during pregnancy influence immunological profiles and neurobehavioral patterns of the offspring. Ann. N.Y. Acad. Sci. 1107, 118-128. doi: 10.1196/annals.1381.013

Porton, B., Greenberg, B. D., Askland, K., Serra, L. M., Gesmonde, J., Rudnick, G., et al. (2013). Isoforms of the Neuronal Glutamate Transporter Gene, SLC1A1/EAAC1, Negatively Modulate Glutamate Uptake: Relevance to Obsessive-Compulsive Disorder. Transl. Psychiatry 3:e259. doi: 10.1038/tp.2013.35

Price, R. A., Kidd, K. K., Cohen, D. J., Pauls, D. L., and Leckman, J. F. (1985). A twin study of Tourette syndrome. Arch. Gen. Psychiatry 42, 815-820. doi: 10.1001/archpsyc.1985.01790310077011

Pryce, C. R., and Feldon, J. (2003). Long-term neurobehavioural impact of the postnatal environment in rats: manipulations, effects and mediating mechanisms. Neurosci. Biobehav. Rev. 27, 57-71. doi: 10.1016/S01497634(03)00009-5

Ralph, R. J., Paulus, M. P., Fumagalli, F., Caron, M. G., and Geyer, M. A. (2001). Prepulse inhibition deficits and perseverative motor patterns in dopamine transporter knock-out mice: differential effects of D1 and D2 receptor antagonists. J. Neurosci. 21, 305-313.

Rapanelli, M., Frick, L. R., Pogorelov, V., Ota, K. T., Abbasi, E., Ohtsu, H., et al. (2014). Dysregulated intracellular signaling in the striatum in a pathophysiologically grounded model of Tourette syndrome. Eur. Neuropsychopharmacol. 24, 1896-1906. doi: 10.1016/j.euroneuro.2014.10.007

Reese, H. E., Scahill, L., Peterson, A. L., Crowe, K., Woods, D. W., Piacentini, J., et al. (2014). The premonitory urge to tic: measurement, characteristics, and correlates in older adolescents and adults. Behav. Ther. 45, 177-186. doi: 10.1016/j.beth.2013.09.002

Robertson, M. M., Eapen, V., and Cavanna, A. E. (2009). The international prevalence, epidemiology, and clinical phenomenology of Tourette syndrome: a cross-cultural perspective. J. Psychosomat. Res. 67, 475-483. doi: 10.1016/j.jpsychores.2009.07.010

Roessner, V., Becker, A., Banaschewski, T., and Rothenberger, A. (2007). Psychopathological profile in children with chronic tic disorder and coexisting ADHD: additive effects. J. Abnorm. Child Psychol. 35, 79-85. doi: 10.1007/s10802-006-9086-z

Rommeck, I., Capitanio, J. P., Strand, S. C., and McCowan, B. (2011). Early social experience affects behavioral and physiological responsiveness to stressful conditions in infant Rhesus Macaques (Macaca Mulatta). Am. J. Primatol. 73, 692-701. doi: 10.1002/ajp.20953

Russo, A. J., and Pietsch, S. C. (2013). Decreased Hepatocyte Growth Factor (HGF) and Gamma Aminobutyric Acid (GABA) in individuals with Obsessive-Compulsive Disorder (OCD). Biomarker Insights 8, 107-114. doi: 10.4137/BMI.S11931

Russo, M., Naro, A., Mastroeni, C., Morgante, F., Terranova, C., Muscatello, M. R., et al. (2014). Obsessive-compulsive disorder: a 'Sensory-Motor' problem? Int. J. Psychophysiol. 92, 74-78. doi: 10.1016/j.ijpsycho.2014.02.007

Sadile, A. G., Lamberti, C., Siegfried, B., and Welzl, H. (1993). Circadian activity, nociceptive thresholds, nigrostriatal and mesolimbic dopaminergic activity in the Naples High- and Low-Excitability rat lines. Behav. Brain Res. 55, 17-27. doi: 10.1016/0166-4328(93)90003-9

Sagvolden, T. (2000). Behavioral validation of the spontaneously hypertensive rat (SHR) as an animal model of attention-deficit/hyperactivity disorder (AD/HD). Neurosci. Biobehav. Rev. 24, 31-39. doi: 10.1016/S0149-7634(99)00058-5

Sagvolden, T., Russell, V. A., Aase, H., Johansen, E. B., and Farshbaf, M. (2005). Rodent models of attention-deficit/hyperactivity disorder. Biol. Psychiatry 57, 1239-1247. doi: 10.1016/j.biopsych.2005.02.002

Scharf, J. M., Yu, D., Mathews, C. A., Neale, B. M., Stewart, S. E., Fagerness, J. A., et al. (2013). Genome-wide association study of Tourette's syndrome. Mol. Psychiatry 18, 721-728. doi: 10.1038/mp.2012.69

Schlander, M., Schwarz, O., Rothenberger, A., and Roessner, V. (2011). Tic disorders: administrative prevalence and co-occurrence with attentiondeficit/hyperactivity disorder in a German community sample. Eur. Psychiatry 26, 370-374. doi: 10.1016/j.eurpsy.2009.10.003

Schmid, C. L., and Bohn, L. M. (2010). Serotonin, but Not N-Methyltryptamines, Activates the Serotonin 2A Receptor via a B-arrestin2/Src/Akt signaling complex in vivo. J. Neurosci. 30, 13513-13524. doi: 10.1523/JNEUROSCI.166510.2010

Schneider, T., Ilott, N., Brolese, G., Bizarro, L., Asherson, P. J., and Stolerman, I. P. (2011). Prenatal exposure to nicotine impairs performance of the 5-choice serial reaction time task in adult rats. Neuropsychopharmacology 36, 1114-1125. doi: 10.1038/npp.2010.249

Shmelkov, S. V., Hormigo, A., Jing, D., Proenca, C. C., Bath, K. G., Milde, T., et al. (2010). Slitrk5 deficiency impairs corticostriatal circuitry and leads to obsessive-compulsive-like behaviors in mice. Nat. Med. 16, 598-602. doi: $10.1038 / \mathrm{nm} .2125$

Siesser, W. B., Zhao, J., Miller, L. R., Cheng, S. Y., and McDonald, M. P. (2006). Transgenic mice expressing a human mutant betal thyroid receptor are hyperactive, impulsive, and inattentive. Genes Brain Behav. 5, 282-297. doi: 10.1111/j.1601-183X.2005.00161.x

Silva, R. R., Munoz, D. M., Barickman, J., and Friedhoff, A. J. (1995). Environmental factors and related fluctuation of symptoms in children and adolescents with Tourette's disorder. J. Child Psychol. Psychiatry 36, 305-312. doi: 10.1111/j.1469-7610.1995.tb01826.x

Simpson, H. B., Shungu, D. C., Bender, J. Jr., Mao, X., Xu, X., Slifstein, M., et al. (2012). Investigation of cortical glutamate-glutamine and $\gamma$-aminobutyric acid 
in obsessive-compulsive disorder by proton magnetic resonance spectroscopy. Neuropsychopharmacology 37, 2684-2692. doi: 10.1038/npp.2012.132

Singer, H. S., Gilbert, D. L., Wolf, D. S., Mink, J. W., and Kurlan, R. (2012). Moving from PANDAS to CANS. J. Pediatrics 160, 725-731. doi: 10.1016/j.jpeds.2011.11.040

Singer, H. S., Mink, J. W., Loiselle, C. R., Burke, K. A., Ruchkina, I., Morshed, S., et al. (2005). Microinfusion of antineuronal antibodies into rodent striatum: failure to differentiate between elevated and low titers. J. Neuroimmunol. 163, 8-14. doi: 10.1016/j.jneuroim.2005.02.018

Singer, H. S., Reiss, A. L., Brown, J. E., Aylward, E. H., Shih, B., Chee, E., et al. (1993). Volumetric MRI changes in Basal Ganglia of children with Tourette's syndrome. Neurology 43, 950-956. doi: 10.1212/WNL.43.5.950

Smicun, Y., Campbell, S. D., Chen, M. A., Gu, H., and Rudnick, G. (1999). The role of external loop regions in serotonin transport. Loop scanning mutagenesis of the serotonin transporter external domain. J. Biol. Chem. 274, 36058-36064. doi: $10.1074 /$ jbc. 274.51 .36058

Smith, S. E., Li, J., Garbett, K., Mirnics, K., and Patterson, P. H. (2007). Maternal immune activation alters fetal brain development through interleukin-6. J. Neurosci. 27, 10695-10702. doi: 10.1523/jneurosci.2178-07.2007

Sowell, E. R., Kan, E., Yoshii, J., Thompson, P. M., Bansal, R., Xu, D., et al. (2008). Thinning of sensorimotor cortices in children with Tourette syndrome. Nat. Neurosci. 11, 637-639. doi: 10.1038/nn.2121

Spessot, A. L., Plessen, K. J., and Peterson, B. S. (2004). Neuroimaging of developmental psychopathologies: the importance of self-regulatory and neuroplastic processes in adolescence. Ann. N.Y. Acad. Sci. 1021, 86-104. doi: 10.1196/annals. 1308.010

Stahl, S. M. (1988). Basal Ganglia neuropharmacology and obsessive-compulsive disorder: the obsessive-compulsive disorder hypothesis of Basal Ganglia dysfunction. Psychopharmacol. Bull. 24, 370-374.

Stead, J. D., Clinton, S., Neal, C., Schneider, J., Jama, A., Miller, S., et al. (2006). Selective breeding for divergence in novelty-seeking traits: heritability and enrichment in spontaneous anxiety-related behaviors. Behav. Genet. 36, 697-712. doi: 10.1007/s10519-0069058-7

Strauss, L., Brink, C. B., Möller, M., Stein, D. J., and Harvey, B. H. (2014). Latelife effects of chronic methamphetamine exposure during puberty on behaviour and corticostriatal mono-amines in social isolation-reared rats. Dev. Neurosci. 36, 18-28. doi: 10.1159/000357495

Sundaram, S. K., Huq, A. M., Wilson, B. J., and Chugani, H. T. (2010). Tourette syndrome is associated with recurrent exonic copy number variants. Neurology 74, 1583-1590. doi: 10.1212/WNL.0b013e3181e0f147

Swedo, S. E., Baird, G., Cook, E. H. Jr., Happé, F. G., Harris, J. C., Kaufmann, W. E., et al. (2012). Commentary from the DSM-5 workgroup on neurodevelopmental disorders. J. Am. Acad. Child Adolesc. Psychiatry 51, 347-349. doi: 10.1016/j.jaac.2012.02.013

Swerdlow, N. R., Shoemaker, J. M., Bongiovanni, M. J., Neary, A. C., Tochen, L. S., and Saint Marie, R. L. (2007). Strain differences in the disruption of prepulse inhibition of startle after systemic and intra-accumbens amphetamine administration. Pharmacol. Biochem. Behav. 87, 1-10. doi: 10.1016/j.pbb.2007.03.014

Swerdlow, N. R., Shoemaker, J. M., Platten, A., Pitcher, L., Goins, J., and Crain, S. (2003). Heritable differences in the effects of amphetamine but not DOI on startle gating in albino and hooded outbred rat strains. Pharmacol. Biochem. Behav. 75, 191-197. doi: 10.1016/S0091-3057(03)00078-9

Swerdlow, N. R., and Sutherland, A. N. (2005). Using animal models to develop therapeutics for Tourette syndrome. Pharmacol. Ther. 108, 281-293. doi: 10.1016/j.pharmthera.2005.05.003

Szechtman, H., Sulis, W., and Eilam, D. (1998). Quinpirole induces compulsive checking behavior in rats: a potential animal model of obsessive-compulsive disorder (OCD). Behav. Neurosci. 112, 1475-1485.

Taj, M. J. R. J., Viswanath, B., Purushottam, M., Kandavel, T., Janardhan Reddy, Y. C., and Jain, S. (2013). DRD4 gene and obsessive compulsive disorder: do symptom dimensions have specific genetic correlates? Prog. NeuroPsychopharmacol. Biol. Psychiatry 41, 18-23. doi: 10.1016/j.pnpbp.2012.10.023

Taylor, J. L., Rajbhandari, A. K., Berridge, K. C., and Aldridge, J. W. (2010). Dopamine receptor modulation of repetitive grooming actions in the rat: potential relevance for Tourette syndrome. Brain Res. 1322, 92-101. doi: 10.1016/j.brainres.2010.01.052
Taylor, J. R., Morshed, S. A., Parveen, S., Mercadante, M. T., Scahill, L., Peterson, B. S., et al. (2002). An animal model of Tourette's syndrome. Am. J. Psychiatry 159, 657-660. doi: 10.1176/appi.ajp.159.4.657

Tizabi, Y., Russell, L. T., Johnson, M., and Darmani, N. A. (2001). Nicotine attenuates DOI-induced head-twitch response in mice: implications for Tourette syndrome. Prog. Neuro-Psychopharmacol. Biol. Psychiatry 25, 1445-1457. doi: 10.1016/S0278-5846(01)00194-4

Udvardi, P. T., Nespoli, E., Rizzo, F., Hengerer, B., and Ludolph, A. G. (2013). Nondopaminergic neurotransmission in the pathophysiology of Tourette syndrome. Int. Rev. Neurobiol. 112, 95-130. doi: 10.1016/B978-0-12-4115460.00004-4

Van Den Buuse, M. (2004). Prepulse inhibition of acoustic startle in spontaneously hypertensive rats. Behav. Brain Res. 154, 331-337. doi: 10.1016/j.bbr.2004.02.021

Wald, R., Dodman, N., and Shuster, L. (2009). The combined effects of memantine and fluoxetine on an animal model of obsessive compulsive disorder. Exp. Clin. Psychopharmacol. 17, 191-197. doi: 10.1037/a0016402

Wan, F. J., and Swerdlow, N. R. (1996). Sensorimotor gating in rats is regulated by different dopamine-glutamate interactions in the nucleus accumbens core and shell subregions. Brain Research 722, 168-176. doi: 10.1016/00068993(96)00209-0

Wang, D. H., Li, W., Liu, X. F., Zhang, J. M., and Wang, S. M. (2013). Chinese medicine formula 'Jian-Pi-Zhi-Dong Decoction' attenuates Tourette syndrome via downregulating the expression of dopamine transporter in mice. Evid. Based Complement. Alternat. Med. 2013:385685. doi: 10.1155/2013/ 385685

Wang, Z., Maia, T. V., Marsh, R., Colibazzi, T., Gerber, A., and Peterson, B. S. (2011). The neural circuits that generate tics in Tourette's syndrome. Am. J. Psychiatry 168, 1326-1337. doi: 10.1176/appi.ajp.2011.09111692

Weiss, I. C., Franklin, T. B., Vizi, S., and Mansuy, I. M. (2011). Inheritable effect of unpredictable maternal separation on behavioral responses in mice. Front. Behav. Neurosci. 5:3. doi: 10.3389/fnbeh.2011.00003

Welch, J. M., Lu, J., Rodriguiz, R. M., Trotta, N. C., Peca, J., Ding, J. D., et al. (2007). Cortico-striatal synaptic defects and OCD-like behaviours in Sapap3-mutant mice. Nature 448, 894-900. doi: 10.1038/nature06104

Woods, A., Smith, C., Szewczak, M., Dunn, R. W., Cornfeldt, M., and Corbett, R. (1993). Selective serotonin re-uptake inhibitors decrease schedule-induced polydipsia in rats: a potential model for obsessive compulsive disorder. Psychopharmacology 112, 195-198. doi: 10.1007/BF02244910

Worbe, Y., Baup, N., Grabli, D., Chaigneau, M., Mounayar, S., McCairn, K., et al. (2009). Behavioral and movement disorders induced by local inhibitory dysfunction in primate striatum. Cereb. Cortex 19, 1844-1856. doi: 10.1093/ cercor/bhn214

Worbe, Y., Mallet, L., Golmard, J. L., Béhar, C., Durif, F., Jalenques, I., Damier, P., et al. (2010). Repetitive behaviours in patients with Gilles de La Tourette syndrome: tics, compulsions, or both? PLoS ONE 5:e12959. doi: 10.1371/journal.pone.0012959

Worbe, Y., Sgambato-Faure, V., Epinat, J., Chaigneau, M., Tandé, D., François, C., et al. (2013). Towards a primate model of Gilles de La tourette syndrome: anatomo-behavioural correlation of disorders induced by striatal dysfunction. Cortex 49, 1126-1140. doi: 10.1016/j.cortex.2012.08.020

Wu, K., Hanna, G. L., Rosenberg, D. R., and Arnold, P. D. (2012). The role of glutamate signaling in the pathogenesis and treatment of obsessive-compulsive disorder. Pharmacol. Biochem. Behav. 100, 726-735. doi: 10.1016/j.pbb.2011.10.007

Xu, M., Kobets, A., Du, J. C., Lennington, J., Li, L., Banasr, M., et al. (2015b). Targeted ablation of cholinergic interneurons in the dorsolateral striatum produces behavioral manifestations of Tourette syndrome. Proc. Natl. Acad. Sci. U.S.A. 112, 893-898. doi: 10.1073/pnas.1419533112

Xu, M., Li, L., Ohtsu, H., and Pittenger, C. (2015a). Histidine decarboxylase knockout mice, a genetic model of tourette syndrome, show repetitive grooming after induced fear. Neurosci. Lett. 595, 50-53. doi: 10.1016/j.neulet.2015.03.067

Yaddanapudi, K., Hornig, M., Serge, R., De Miranda, J., Baghban, A., Villar, G., et al. (2010). Passive transfer of streptococcus-induced antibodies reproduces behavioral disturbances in a mouse model of pediatric autoimmune neuropsychiatric disorders associated with streptococcal infection. Mol. Psychiatry 15, 712-726. doi: 10.1038/mp.2009.77 
Yan, T. C., Hunt, S. P., and Stanford, S. C. (2009). Behavioural and neurochemical abnormalities in mice lacking functional tachykinin-1 (NK1) receptors: a model of attention deficit hyperactivity disorder. Neuropharmacology 57, 627-635. doi: 10.1016/j.neuropharm.2009.08.021

Zalcman, S. S., Patel, A., Mohla, R., Zhu, Y., and Siegel, A. (2012). Soluble cytokine receptors (sIL-2R $\alpha$, sIL-2R $\beta$ ) induce subunit-specific behavioral responses and accumulate in the cerebral cortex and basal forebrain. PLoS ONE 7:e36316. doi: 10.1371/journal.pone.0036316

Zebardast, N., Crowley, M. J., Bloch, M. H., Mayes, L. C., Wyk, B. V., Leckman, J. F., et al. (2013). Brain mechanisms for prepulse inhibition in adults with tourette syndrome: initial findings. Psychiatry Res. 214, 33-41. doi: 10.1016/j.pscychresns.2013.05.009

Zhang, D., Patel, A., Zhu, Y., Siegel, A., and Zalcman, S. S. (2012). Antistreptococcus IgM antibodies induce repetitive stereotyped movements: cell activation and co-localization with $\mathrm{Fc} \alpha / \mu$ receptors in the striatum and motor cortex. Brain Behav. Immun. 26, 521-533. doi: 10.1016/j.bbi.2012. 01.005

Zhu, F., Liu, Y., Zhao, J., and Zheng, Y. (2014). Minocycline alleviates behavioral deficits and inhibits microglial activation induced by intrahippocampal administration of granulocyte-macrophage colony-stimulating factor in adult rats. Neuroscience 266, 275-281. doi: 10.1016/j.neuroscience.2014. 01.021

Zhu, J., Zhang, X., Xu, Y., Spencer, T. J., Biederman, J., and Bhide, P. G. (2012). Prenatal nicotine exposure mouse model showing hyperactivity, reduced cingulate cortex volume, reduced dopamine turnover, and responsiveness to oral methylphenidate treatment. J. Neurosci. 32, 9410-9418. doi: 10.1523/JNEUROSCI.1041-12.2012

Zimmermann, A. M., Jene, T., Wolf, M., Görlich, A., Gurniak, C. B., SassoèPognetto, M., et al. (2014). Attention-deficit/hyperactivity disorder-like phenotype in a mouse model with impaired actin dynamics. Biol. Psychiatry 78, 95-106. doi: 10.1016/j.biopsych.2014.03.011

Conflict of Interest Statement: The authors declare that the research was conducted in the absence of any commercial or financial relationships that could be construed as a potential conflict of interest.

The reviewer KRMV is a co-Topic Editor of the handling Editor for the Research Topic this article is published under. The authors and the handling Editor declared an ongoing co-authorship, and the handling Editor states that the process nevertheless met the standards of a fair and objective review.

Copyright (C) 2016 Nespoli, Rizzo, Boeckers, Hengerer and Ludolph. This is an openaccess article distributed under the terms of the Creative Commons Attribution License (CC BY). The use, distribution or reproduction in other forums is permitted, provided the original author(s) or licensor are credited and that the original publication in this journal is cited, in accordance with accepted academic practice. No use, distribution or reproduction is permitted which does not comply with these terms. 